\title{
An Inventory Model for Growing Items with Imperfect Quality When the Demand Is Price Sensitive under Carbon Emissions and Shortages
}

\author{
Cynthia Griselle De-la-Cruz-Márquez, Leopoldo Eduardo Cárdenas-Barrón (D), \\ and Buddhadev Mandal
}

Tecnologico de Monterrey, School of Engineering and Sciences, Ave. Eugenio Garza Sada 2501, Monterrey 64849, NL, Mexico

Correspondence should be addressed to Leopoldo Eduardo Cárdenas-Barrón; lecarden@tec.mx

Received 3 December 2020; Revised 17 February 2021; Accepted 24 February 2021; Published 8 April 2021

Academic Editor: Shib S. Sana

Copyright (c) 2021 Cynthia Griselle De-la-Cruz-Márquez et al. This is an open access article distributed under the Creative Commons Attribution License, which permits unrestricted use, distribution, and reproduction in any medium, provided the original work is properly cited.

\begin{abstract}
Nowadays, it is well known that global warming is a great hazard to the planet, and the carbon emissions are a principal source of global warming. For this reason, the customers have become more environment and quality conscious than before, and as a result, they request the firms to be ecofriendly. In this context, it is desirable that companies develop and implement inventory models which consider sustainability issues. Furthermore, the companies face problems of shortages and setting prices in order to persist in a competitive and challenging business. Besides, there exists a kind of items different than the traditional products that it is necessary to feed them until a target weight is reached in order to slaughter and sell to customers. These are named as growing items. In this sense, this research work proposes an inventory model for growing items with imperfect quality when the demand is price sensitive under carbon emissions and shortages. The shortages are fully backordered. The demand is price sensitive according to a polynomial function. The proposed inventory model determines jointly the optimal policy for the selling price of perfect-quality growing items, the order quantity, and the backordering quantity which maximize the expected total profit per unit of time. Some numerical examples are resolved in order to illustrate the use and the applicability of the inventory model. Finally, a sensitivity analysis is conducted and some managerial insights are given.
\end{abstract}

\section{Introduction}

Inventory management is a valued function for all firms. The main purpose of the inventory management department is to control the materials from the acquisition to sale, taking decisions of how much and when to buy the items avoiding excess or unplanned stockout.

Since the introduction of the classical economic order quantity (EOQ) inventory model proposed by Harris [1], industries have shown great interest in the development of inventory control models with new features. For example, Ghosh et al. [2] built an inventory model for a deteriorating production system when there are random machine breakdowns considering that there exists a selling price discount. Manna et al. [3] studied the impacts of inspection errors on an imperfect production-inventory model when the demand rate depends on both selling-price discount and warranty time. Khan et al. [4] and Shaikh et al. [5] introduced a two-warehouse inventory model for instantaneously deteriorating goods considering an advance payment agreement. In the same research direction, Khan et al. [6] investigated the effects of noninstantaneous deterioration on the ordering decisions for a two-warehouse inventory system taking into consideration an advance payment scheme. Shaikh et al. [7] developed an EOQ inventory model for deteriorating goods with stock-dependent demand when there exists a price discount facility.

It is well known that the EOQ determines the optimal order quantity to minimize total inventory costs. Although this inventory model has the groundwork for inventory 
systems, it has unrealistic assumptions. For that reason, many researchers have incorporated different characteristics in order to model real world applications such as imperfect quality, carbon emissions reduction, growing items, shortages, and pricing, among others.

Harris's [1] inventory model assumes that all items are of perfect quality. However, this assumption not always occurs because the majority of the manufacturing processes generate a portion of imperfect quality items. So, Salameh and Jaber [8] formulated an EOQ inventory model considering that the ordered lot contains imperfect-quality items and these items are sold as a single batch at a lower price. Cárdenas-Barrón [9] identified and corrected an error in the inventory model presented by Salameh and Jaber [8]. Wee et al. [10] extended Salameh and Jaber's [8] inventory model by incorporating shortages with full backordering. Afterwards, Maddah and Jaber [11] detected and rectified one flaw in Salameh and Jaber's [8] inventory model. The flaw is in the manner of determining the expected total profit per unit of time $(E[T P U])$. Salameh and Jaber [8] utilized the equation $E[\mathrm{TPU}]=E[\mathrm{TP} / T]$ which is not exact. The research work of Wee et al. [10] contains the same flaw. It is important to remark that the process of producing the profit is a renewal process with renewal points at order placement periods. Therefore, in order to calculate the expected total profit per unit of time, it is needed to apply the well-known elementary renewal reward theorem given by Ross [12]. For this reason, the expected total profit per unit of time must be computed with the following equation: $E[\mathrm{TPU}]=E[\mathrm{TP}] / E[T]$. Chang and Ho [13] revisited and rescued Wee et al.'s [10] inventory model by applying the well-known elementary renewal reward theorem to get the expected total profit per unit time. Cárdenas-Barrón [14] derived closed-form expressions to determining the optimal solution to an EOQ inventory model considering items with imperfect quality. Ghiami and Beullens [15] developed a production-inventory model for a deteriorating product with partial backordering using a cashflow net present value analysis. They generated managerial insights related if it is convenient financially to have planned shortages with partial backordering and lost sales. Zhou et al. [16] developed an economic-order quantity model considering shortages, imperfect quality, and inspection errors. Taleizadeh et al. [17] studied an inventory model when the lot contains imperfect-quality items, and these cannot be replaced with perfect-quality ones immediately, but these are repaired and then they are sold at lower price. In this line of research, Rezaei [18] introduced an inventory model considering imperfect-quality items. Sampling inspection plans are designed so the buyer would be able to decide regarding the next step.

At the present time, as we know, global warming is a big threat to the world and carbon emissions are a leading cause of global warming. For this reason, the sustainability is an extremely significant concern for all people that desire to maintain the planet healthy. It is well known that industries generate large amounts of carbon emissions. Furthermore, the transportation of goods through the supply chains produces carbon emissions too. Consequently, these damage the environment and cause global warming at the same time.
In this context, the governments of the countries have imposed strict policies that limit the amounts of carbon emissions with the aim of having a sustainable environment free of pollution. The regulations related to avoid pollution impose additional costs to firms; thus, it is convenient for these to adapt and obey the regulations. In this direction, several companies have adopted inventory models that consider reducing carbon emissions. For example, Hua et al. [19] investigated how companies manage carbon emissions in an inventory management. Arslan and Turkay [20] integrated sustainability features into the design of an inventory model and proposed different policies that include environmental and social criteria. Battini et al. [21] introduced a sustainable EOQ inventory model integrating factors that have a great impact on the environment. Lin and Sarker [22] presented an inventory model that considers carbon tax policy and imperfect-quality items avoiding shortages and incorporated and evaluated some carbon tax systems. Tiwari et al. [23] investigated an integrated vendorbuyer inventory model for deteriorating goods with imperfect quality, taking into account that all processes in the supply chain cause carbon emissions. The target of their inventory model is to decrease the ecological effects. Kazemi et al. [24] proposed an inventory model with imperfect quality from a sustainable point of view, and the aim is to know the impact of emission costs into the total profit. Modak et al. [25] addressed a manufacturer-retailer supply chain inventory model by considering that there is a cost of GHG emission of the production system and determined the optimal pricing policies. Afterwards, Sinha and Modak [26] presented an economic production quantity (EPQ) inventory model taking into account aspects of carbon emissions and carbon trading. Li and Hai [27] studied an inventory system for a warehouse with multiple retailers considering carbon emissions. Manna et al. [28] constructed a production-inventory model for controlling the GHG emissions when the pollution parameters are fuzzy. Later, Manna et al. [29] studied the effects of carbon emissions on an imperfect production-inventory model. Huang et al. [30] proposed an inventory model for a two-echelon supply chain considering that all operations within the chain produce carbon emissions. Their inventory model helps companies to determine the optimal production quantity and delivery quantity which minimize the total costs under different carbon emission policies. Recently, Mishra et al. [31] revised the standard EOQ inventory model to integrate sustainability matters and developed three inventory models with and without shortage situations. Medina-Santana and Cárdenas-Barrón [32] formulated an inventory model considering a discontinuous transportation cost function and carbon emissions function. The most recent investigation about carbon emissions belongs to the authors Modak and Kelle [33]. They proposed to apply the social work donation as a scheme of corporate social responsibility into a closed-loop supply chain, taking into consideration the carbon emission tax and that demand is uncertain.

In recent years, a new topic, that is, inventory management for growing items, has also been included in the derivation of inventory models. A growing item is a kind of 
product which is capable of growth during time like farmyard animals, unlike inert products that do not increase in weight during storage. Growing items are incorporated for first time in an EOQ inventory model by Rezaei [34]. Here, the weight increment of items is the main difference between the inventory models proposed by Rezaei [34] and Harris [1]. Rezaei [34] developed an EOQ for growing items for different types of animals, specifically for a kind of poultry. Zhang et al. [35] revisited and extended the research work of Rezaei [34] by creating an inventory model for growing items reducing the carbon emissions in operations. Sebatjane [36] presented three inventory models for growing items. Afterwards, Khalilpourazari and Pasandideh [37] worked with growing items too. They formulated a mathematical model for multi-item economic order quantity subjected to some operational constrains. Nobil et al. [38] derived an EOQ inventory model for growing items when the shortages are allowed, and these are fully backordered. They argued that their inventory model helps poultry industries. Under an environment of a two-echelon supply chain composed by one supplier and one farmer, Malekitabar et al. [39] developed an inventory model for growing mortal items considering both the growth function and the mortality rate for the items. Recently, Sebatjane and Adetunji [40] presented an EOQ inventory model for growing items with imperfect quality. It is assumed that a certain fraction of the growing items has lower quality than desired. They mentioned that it is necessary to define the growth function of the items in order to calculate the feeding cost. In this context, Sebatjane and Adetunji [40] considered three growth functions: logistic, linear, and split linear. In the same year, Sebatjane and Adetunji [41] introduced an economic-order quantity inventory model for growing items with incremental quantity discounts. They proposed an optimal inventory policy to minimize the total inventory cost in both the owned and rented facilities. Sebatjane and Adetunji [42] continued working with growing items, but in this case, they formulated an inventory control model more realistically, considering that the items need to be transformed and packaged into a consumable form before customer demand is met. The next year, Sebatjane and Adetunji [43] built a model for managing inventory in a perishable food products supply chain that begins with farming operations where growing items live and finishes with the consumption of processed inventory. Sebatjane and Adetunji [44] derived an inventory model for a four-echelon supply chain with farming, processing, screening, and retail operations. Gharaei and Almehdawe [45] provided an economic growing quantity (EGQ) inventory model to determine the optimal economic growth and slaughter period and the economic growing quantity to minimize the total cost of the inventory system. Hidayat et al. [46] presented an EOQ inventory model with a capacitated warehouse facility and limited budget for growing products when the seller provides an incremental quantity discounts scheme. Mokhtari et al. [47] addressed a production-inventory model for growing goods which deteriorate through time. Nishandhi [48] studied an EOQ inventory model with budget-capacity constraint for growing items when a portion of the items are of imperfect quality. Pourmohammad-Zia and Karimi [49] determined the optimal replenishment and breeding policies for growing products. Afzal and Alfares [50] and Alfares and Afzal [51] developed EOQ inventory models for growing items considering shortages with full backordering. Recently, Sebatjane and Adetunji [52] created an inventory model for growing items under a three-echelon supply chain environment taking into account farming, processing, and retail echelons. Table 1 shows the inventory models related with growing items.

The organizations need to determine the optimal selling prices for the products in order to encourage that the customers buy more and more products, and therefore, these organizations can survive in the competitive business environment. In this context, the academicians and researchers are modelling the demand rate as dependent of price. For example, Khan et al. [53] analyzed two supply chain inventory systems when the demand rate depends on price. Khan et al. [54] proposed an inventory model for deteriorating merchandises when the demand is price sensitive, and there exists a discount policy according all-units arrangement. Khan et al. [55] developed inventory models for perishable products when the demand rate is dependent on both price and advertisement. On the one hand, Khan et al. [56] examined the effects of an advance payment with discount facility on ordering decisions for perishable items taking into account that the demand rate is both price and stock dependent. On the other hand, Panda et al. [57] dealt with a two-warehouse system for deteriorating items when the demand rate is dependent on both price and stock; however, the price is not optimized. Sinha et al. [58] formulated an entropic-order quantity inventory model when the demand of the product is dependent on selling price and there is an inspection process to split the imperfect-quality products from the perfect ones. Modak [59] and Modak and Kelle [60] introduced omni- and dual-channel supply chain models, respectively, by considering that there exists a priceand delivery-time-sensitive stochastic demand.

Nowadays, the firms face problems of shortages and setting the selling price in order to survive in a competitive business, which is becoming more challenging day by day. Moreover, the customers are more quality and environmental conscious than before, and therefore, they demand products of perfect quality and request firms to minimize the carbon emissions to the environment. However, the firms always face problems of process quality and contaminate the planet. Besides, there exists a type of goods different than the conventional products which requires feeding until a target weight is reached in order to slaughter and sell to customers. These are named as growing items (chickens, cows, pigs, goats, fish, shrimps, etc.). In this direction, this research work develops an inventory model for growing items with imperfect quality when the demand is price sensitive under carbon emissions and shortages. The shortages are fully backordered. The demand is price sensitive according to a polynomial function. The proposed inventory model determines jointly the optimal policy for the selling price of perfect-quality growing items, the order quantity, and 
TABLE 1: Inventory models with growing items.

\begin{tabular}{|c|c|c|c|c|c|c|c|c|}
\hline Authors & $\begin{array}{c}\text { Price- } \\
\text { dependent } \\
\text { demand }\end{array}$ & $\begin{array}{l}\text { Type of price- } \\
\text { dependent } \\
\text { demand }\end{array}$ & $\begin{array}{l}\text { Allowed } \\
\text { shortages }\end{array}$ & $\begin{array}{c}\text { Type of } \\
\text { backordering }\end{array}$ & $\begin{array}{l}\text { Imperfect } \\
\text { quality }\end{array}$ & $\begin{array}{l}\text { Carbon } \\
\operatorname{tax}\end{array}$ & $\begin{array}{l}\text { Type of } \\
\text { objective } \\
\text { function }\end{array}$ & Optimize \\
\hline Rezaei [34] & No & - & No & - & No & No & Max. profit & $\begin{array}{c}\text { Order quantity and } \\
\text { slaughter time }\end{array}$ \\
\hline Zhang et al. [35] & No & - & No & - & No & Yes & Min. cost & $\begin{array}{c}\text { Order quantity and } \\
\text { slaughter time }\end{array}$ \\
\hline \multirow{3}{*}{ Sebatjane [36] } & No & - & No & - & Yes & No & Max. profit & $\begin{array}{l}\text { Order quantity and } \\
\text { cycle time }\end{array}$ \\
\hline & No & - & No & - & No & No & Min. cost & $\begin{array}{c}\text { Order quantity and } \\
\text { cycle time }\end{array}$ \\
\hline & No & - & No & - & No & No & Min. cost & $\begin{array}{c}\text { Order quantity and } \\
\text { cycle time }\end{array}$ \\
\hline $\begin{array}{l}\text { Khalilpourazari and } \\
\text { Pasandideh [37] }\end{array}$ & No & - & No & - & No & No & Max. profit & $\begin{array}{l}\text { Order quantity and } \\
\text { slaughter time }\end{array}$ \\
\hline Nobil et al. [38] & No & - & Yes & Full & No & No & Min. cost & $\begin{array}{c}\text { Order quantity, } \\
\text { backordering } \\
\text { quantity, and cycle } \\
\text { time }\end{array}$ \\
\hline $\begin{array}{l}\text { Malekitabar et al. } \\
\text { [39] }\end{array}$ & Yes & Linear & No & - & No & No & Max. profit & $\begin{array}{l}\text { Selling price and } \\
\text { cycle time }\end{array}$ \\
\hline $\begin{array}{l}\text { Sebatjane and } \\
\text { Adetunji [40] }\end{array}$ & No & - & No & - & Yes & No & Max. profit & $\begin{array}{c}\text { Order quantity and } \\
\text { cycle time }\end{array}$ \\
\hline $\begin{array}{l}\text { Sebatjane and } \\
\text { Adetunji [41] }\end{array}$ & No & - & No & - & No & No & Min. cost & $\begin{array}{l}\text { Order quantity and } \\
\text { cycle time }\end{array}$ \\
\hline $\begin{array}{l}\text { Sebatjane and } \\
\text { Adetunji [42] }\end{array}$ & No & - & No & - & No & No & Min. cost & $\begin{array}{l}\text { Order quantity, } \\
\text { cycle time, and } \\
\text { number of } \\
\text { shipments }\end{array}$ \\
\hline $\begin{array}{l}\text { Sebatjane and } \\
\text { Adetunji [43] }\end{array}$ & Yes & Exponential & No & - & No & No & Max. profit & $\begin{array}{l}\text { Selling price, order } \\
\text { quantity, cycle time, } \\
\text { and number of } \\
\text { shipments }\end{array}$ \\
\hline $\begin{array}{l}\text { Sebatjane and } \\
\text { Adetunji [44] }\end{array}$ & No & - & No & - & Yes & No & Max. profit & $\begin{array}{l}\text { Order quantity, } \\
\text { cycle time, and } \\
\text { number of } \\
\text { shipments }\end{array}$ \\
\hline $\begin{array}{l}\text { Gharaei and } \\
\text { Almehdawe [45] }\end{array}$ & No & - & No & - & No & No & Min. cost & $\begin{array}{l}\text { Order quantity and } \\
\text { cycle time }\end{array}$ \\
\hline Hidayat et al. [46] & No & - & No & - & No & No & Min. cost & $\begin{array}{c}\text { Order quantity and } \\
\text { cycle time }\end{array}$ \\
\hline Mokhtari et al. [47] & No & - & No & - & No & No & Max. profit & $\begin{array}{c}\text { Order quantity and } \\
\text { slaughter time }\end{array}$ \\
\hline Nishandhi [48] & No & - & Yes & Full & Yes & No & Min. cost & $\begin{array}{c}\text { Order quantity, } \\
\text { backordering } \\
\text { quantity, and cycle } \\
\text { time }\end{array}$ \\
\hline $\begin{array}{l}\text { Pourmohammad- } \\
\text { Zia and Karimi [49] }\end{array}$ & No & - & No & - & Yes & No & Min. cost & $\begin{array}{l}\text { Order quantity and } \\
\text { cycle time }\end{array}$ \\
\hline $\begin{array}{l}\text { Afzal and Alfares } \\
{[50]}\end{array}$ & No & - & Yes & Full & Yes & No & Min. cost & $\begin{array}{c}\text { Order quantity, } \\
\text { backordering } \\
\text { quantity, and cycle } \\
\text { time }\end{array}$ \\
\hline $\begin{array}{l}\text { Alfares and Afzal } \\
\text { [51] }\end{array}$ & No & - & Yes & Full & Yes & No & Min. cost & $\begin{array}{c}\text { Order quantity, } \\
\text { backordering } \\
\text { quantity, and cycle } \\
\text { time }\end{array}$ \\
\hline $\begin{array}{l}\text { Sebatjane and } \\
\text { Adetunji [52] }\end{array}$ & No & - & No & - & No & No & Max. profit & $\begin{array}{l}\text { Order quantity, } \\
\text { cycle time, and } \\
\text { number of } \\
\text { shipments }\end{array}$ \\
\hline This paper & Yes & Polynomial & Yes & Full & Yes & Yes & Max. profit & $\begin{array}{c}\text { Selling price, order } \\
\text { quantity, } \\
\text { backordering } \\
\text { quantity, and cycle } \\
\text { time }\end{array}$ \\
\hline
\end{tabular}


backordering quantity which maximize the total profit per unit of time.

The remaining parts of this research work are described as follows: Section 2 introduces the notation defining symbols for the parameters, decision variables, decisiondependent variables, and functions. Section 3 states the assumptions under which the inventory model is built. Section 4 formulates the inventory model with shortages for growing items with imperfect quality when the demand is price sensitive considering carbon emissions. Section 5 determines some theoretical results, develops the solution procedure to determine the optimal solution to the inventory problem, and identifies some inventory models as special cases. Section 6 solves some numerical examples. Section 7 provides a sensitivity analysis and some managerial insights. Section 8 gives some conclusions and summaries several research points that can be addressed in the near future.

\section{Notations}

With the aim of having a standard notation for the inventory models with growing items, the nomenclature of Sebatjane and Adetunji [40] is used and extra symbols are defined too. Therefore, the following notations are adopted in order to develop the inventory model for growing items with imperfect quality, carbon emissions, and planned shortages.

\subsection{Parameters. $\pi$ : Scale parameter for the price-de- pendent demand}

$\rho$ : Sensitivity parameter for the price-dependent demand $n$ : Demand power index

$v$ : Selling price of imperfect items (currency symbol/ unit of weight)

$K$ : Setup cost (currency symbol/cycle)

$h$ : Holding cost (currency symbol/unit of weight/unit of time)

$b$ : Shortage cost (currency symbol/unit of weight/unit of time)

c: Feeding cost (currency symbol/unit of weight)

$p$ : Purchasing cost (currency symbol/unit of weight)

$z$ : Inspection cost (currency symbol/unit of weight)

$\theta$ : Carbon tax rate (currency symbol/amount of carbon emissions)

Ec: Carbon emissions cost (currency symbol)

$\widehat{K}$ : Amount of carbon emissions produced during the setup process (unit of weight/unit of time)

$\hat{h}$ : Amount of carbon emissions caused by holding items in the warehouse (unit of weight/unit of time)

$\widehat{c}$ : Amount of carbon emissions generated during the feeding period (unit of weight/unit of time)

$\bar{p}$ : Amount of carbon emissions made during the purchasing activity (unit of weight/unit of time) $\bar{z}$ : Amount of carbon emissions created during the inspection process (unit of weight/unit of time)

$r$ : Inspection rate (unit of weight/unit of time)

$\alpha$ : Asymptotic weight of each item (unit of weight)

$\beta$ : Integration constant (numeric value)

$\lambda$ : Growth rate (numeric value/unit of time)

$x$ : Percentage of slaughtered items that are of imperfect quality $(0 \leq x \leq 1)$

$E[x]$ : Expected value of the percentage of imperfect items $(0 \leq E[x] \leq 1)$

$1-E[x]$ : Expected value of the percentage of perfect items $(0 \leq 1-E[x] \leq 1)$

$w_{0}$ : Weight of a newborn item (unit of weight)

$w_{1}$ : Target weight of a grown item (unit of weight)

$w_{t}$ : Weight of an item at time $t$ (unit of weight)

$t_{1}$ : Growing period (unit of time)

$t_{2}$ : Inspection period for the backordering quantity $(B)$ (unit of time)

$t_{3}$ : Inspection period for $y w_{1}-B$ units of weight (unit of time)

$t_{4}$ : Consumption period of perfect items after inspection time (unit of time)

$t_{5}$ : Shortages accumulation period (unit of time)

Decision variables:

$y$ : Order quantity of newborn items (units)

$B$ : Backordering quantity (unit of weight)

$s$ : Selling price of perfect items (currency symbol/unit of weight)

Decision-dependent variables:

$T$ : Cycle time (unit of time)

$Q_{0}$ : Total weight at the beginning of the growing period, $Q_{0}=y w_{0}$ (unit of weight)

$Q_{t_{1}}$ : Total weight at the end of the growing period $t_{1}$, $Q_{t_{1}}=y w_{1}$ (unit of weight)

Functions:

$D(s)$ : Price-dependent demand function (unit of weight/unit of time)

$w_{t}(t)$ : Growth function

$g(x)$ : Probability density function of the percentage of imperfect items

$\operatorname{TPU}(y, B, s)$ : Total profit (currency symbol/unit of time)

\section{Assumptions}

The inventory model is based on the following assumptions:

(1) The planning horizon is infinite and a single kind of items is purchased, and these are capable of growing before the slaughter process.

(2) The shortages are permitted, and these are completely backordered. 
(3) The items are slaughtered and are immediately inspected in order to sell them to consumers. Firstly, the backordering quantity is inspected in order to cover the shortages of the previous cycle.

(4) There exists an inspection process that is $100 \%$ effective.

(5) A random percentage of the slaughtered items is of imperfect quality.

(6) Imperfect-quality items are not reworked or replaced.

(7) All imperfect-quality items are salvaged and sold as a single lot at the end of the inspection process.

(8) The feeding cost for growing the items is directly related to weight gained by these.

(9) The holding cost to keep a weight unit of the slaughtered item in storage is incurred during both the inspection process and the consumption period.

(10) The demand rate $D(s)$ is a polynomial function of selling price of the perfect-quality items. It is as follows: $D(s)=\pi-\rho s^{n}$.

(11) The selling price of perfect-quality items is optimized, and it must be greater than that of the imperfect-quality items.

(12) Carbon emissions are taken into account, and these occur in all operations of the inventory system, except in the shortage period.

\section{Inventory Model Development}

The inventory model for growing items with imperfect quality, carbon emissions, and shortages is depicted in Figure 1. Consider a situation where a company orders $y$ newborn growing items from an outside supplier at the beginning of the growing period $t_{1}$. Each newborn growing item has an initial weight of $w_{0}$. In this moment, the total initial weight of the inventory is $Q_{0}=y w_{0}$. The growing items are fed, and eventually, they grow through time until an objective weight of $w_{1}$ is attained. Then, the growing items are slaughtered at the end of the growing time $t_{1}$. At this point, the final weight of the inventory is $Q_{t_{1}}=y w_{1}$, and this total weight contains a percentage $x$ of imperfect items. The portion of imperfect items is a random variable with a known probability density distribution $f(x)$, and its expected value is $E[x]$. The shortages are permitted, and these are fully backordered. Therefore, immediately, the inspection process starts to screen the items to complete the backordering quantity $(B)$ at a rate of $r$ units of weight per unit of time during the period $t_{2}$ in order to satisfy immediate shortages from the previous cycle. So, at the end of the inspection period $t_{2}$, the inventory model diminishes vertically by $B$ units of weight. It is important to remark that the items continue to be inspected at the same rate $r$ during the period $t_{3}$ till the total weight is screened. The length of the inspection time is $t_{2}+t_{3}$. It is worth mentioning that, for the duration of $t_{3}$, the on-hand inventory declines by both removing the imperfect items and current demand rate. At the end of period $t_{3}$, the imperfect items are salvaged and sold as a single lot with a less price. Consequently, the onhand inventory drops vertically by $x y w_{1}$ units of weight. On the other hand, in the course of $t_{4}$, the on-hand inventory decreases due to the current demand rate. The inventory level continues gradually consuming until it reaches zero at the end of period $t_{4}$ and the shortages period starts. As a final point, during $t_{5}$, the shortages are accumulated at the current demand rate which are eventually satisfied in the next cycle. Without loss of generality and with the purpose to make the mathematical expressions more tractable, the cycle time is determined as follows: $T=t_{3}+t_{4}+t_{5}$.

Throughout $t_{1}$, the items are growing according to a logistic growth function which relates the weight of items with time using three input parameters. These input parameters are the asymptotic weight of the items, the integration constant, and the growth rate, which are represented by $\alpha, \beta$, and $\lambda$, respectively. Thus, the logistic growth function of the items is mathematically expressed by

$$
w_{t}(t)=\frac{\alpha}{1+\beta e^{-\lambda t}} .
$$

As it was mentioned above, the growing items are slaughtered when their weight attains the objective weight of $w_{1}$ which occurs at the end of the growth period $t_{1}$. Hence,

$$
w_{1}=w_{t}\left(t=t_{1}\right)=\frac{\alpha}{1+\beta e^{-\lambda t_{1}}} .
$$

The duration of the growth period $\left(t_{1}\right)$ is calculated by solving equation (2) for $t_{1}$. Thus,

$$
t_{1}=-\frac{\ln \left[(1 / \beta)\left(\left(\alpha / w_{1}\right)-1\right)\right]}{\lambda} .
$$

The inventory must be inspected before being sold in order to avoid to vend imperfect quality as good ones; therefore, firstly, the backordering quantity $(B)$ of the previous cycle must be screened at an inspection rate $r$. Therefore, the duration of the inspection period $\left(t_{2}\right)$ is computed as follows:

$$
t_{2}=\frac{B}{r}
$$

After the inspection of the backordering quantity is conducted, the screening process continues until the total weight is screened due to the fact that there are pending $y w_{1}-B$ units of weight to be inspected. This is performed during the inspection time $t_{3}$ which is given as follows:

$$
t_{3}=\frac{y w_{1}-B}{r} \text {. }
$$

After the inspection time $t_{3}$, the imperfect-quality items are withdrawn from the storage and sold. Now, the on-hand inventory contains only perfect-quality items, and these are consumed during $t_{4}$. The time $t_{4}$ is determined as follows:

$$
E\left[t_{4}\right]=\frac{y w_{1}-B-D t_{3}-E[x] y w_{1}}{D(s)} .
$$

The shortages accumulation period $\left(t_{5}\right)$ is obtained with 


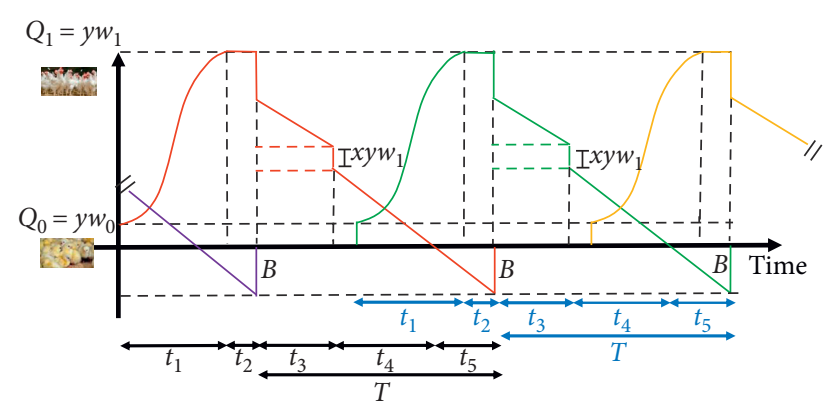

FIGURE 1: Inventory behavior for growing items with imperfect quality and shortages.

$$
t_{5}=\frac{B}{D(s)}
$$

With the aim to have more manageable equations and without loss of generality, it is defined that the expected cycle time $T$ is computed by the sum of $t_{3}, t_{4}$, and $t_{5}$. From equations (5)-(7), the expected cycle time $E[T]$ is calculated as

$$
E[T]=t_{3}+E\left[t_{4}\right]+t_{5}=\frac{y w_{1}(1-E[x])}{D(s)} .
$$

The main goal of the inventory model for growing items with imperfect quality, carbon emissions, and shortages is to determine the optimal values for the selling price, order quantity, and backordering quantity that maximize the total profit of the company. The total profit is obtained by the difference between the total revenue and the total cost of the inventory system. The details of how to calculate each component of the total revenue and the total cost are given below.

4.1. Expected Revenue per Period. Due to the fact that the company vends both perfect- and imperfect-quality items, for that reason, the expected total revenue $E$ [TR] is calculated by the sum of total sales of imperfect and perfect items. The perfect-quality items are sold at a price of $s$ per unit of weight, while at the end of the inspection period $t_{3}$, the imperfect-quality items are vended as a single batch with a less price of $v$ per unit of weight. As a result, the expected total revenue $E[\mathrm{TR}]$ per period is given by

$$
E[\mathrm{TR}]=s y w_{1}(1-E[x])+v y w_{1} E[x] .
$$

4.2. Total Cost per Period. The expected total cost E[TC] per period includes the purchasing cost, setup cost, feeding cost, expected holding cost, inspection cost, backordering cost, and expected carbon emissions cost. One has

$$
E[\mathrm{TC}]=P c+S c+F c+E[H c]+Z c+B c+E[E c] .
$$

The objective of this inventory model is to maximize the expected total profit $E[\mathrm{TP}]$ which is obtained by subtracting the expected total cost per period $E[T C]$ from the expected total revenue $E[\mathrm{TR}]$ per period. Then,
$E[\mathrm{TP}]=E[\mathrm{TR}]-P c-S c-F c-E[H c]-Z c-B c-E[E c]$.

The following section provides a detailed discussion of the calculations of the aforesaid costs.

4.3. Purchasing Cost per Period. At the beginning of each period, the company buys $y$ newborn items at a cost of $p$ per unit of weight; each one with a weight of $w_{0}$. Thus, the purchasing cost per period is obtained with

$$
P c=p y w_{0} .
$$

4.4. Setup Cost per Period. At the commencement of each period, a setup cost of $K$ is carried out. So, the setup cost per period is determined as

$$
S c=K
$$

4.5. Feeding Cost per Period. The growing items are fed during $t_{1}$, and a feeding cost is incurred by the company at $c$ per unit of weight. As the growing items become older and bigger, they need more food. For that reason, the quantity of food consumed by the items depends on the age (weight) of the items according to the growth function $w_{t}(t)$. The feeding cost per period is calculated with

$$
\begin{aligned}
F c & =c y \int_{0}^{t_{1}} w_{t_{1}}(t) \mathrm{d} t=c y \int_{0}^{t_{1}}\left(\frac{\alpha}{1+\beta e^{-\lambda t}}\right) \mathrm{d} t \\
& =c y\left(\alpha t_{1}+\frac{\alpha}{\lambda}\left[\ln \left(1+\beta e^{-\lambda t_{1}}\right)-\ln (1+\beta)\right]\right) .
\end{aligned}
$$

4.6. Expected Holding Cost per Period. The company incurs in a holding cost for maintaining in good conditions the items in storage during the cycle time $T$. The expected holding cost is determined by multiplying the holding cost (h) per unit of weight per unit of time by the inventory carried out during $t_{2}+t_{3}+t_{4}$. The whole inventory held is calculated as the sum of the areas $A_{1}+A_{2}+A_{3}+A_{4}+A_{5}$ (see Figure 5 in Appendix A). So, the expected holding cost is given by

$$
\begin{aligned}
E[H c]= & h\left[\frac{y^{2} w_{1}^{2} E\left[(1-x)^{2}\right]}{2 D(s)}-\frac{y w_{1}(1-E[x]) B}{D(s)}\right. \\
& \left.+\frac{B^{2}}{2 D(s)}+\frac{y^{2} w_{1}^{2} E[x]}{r}-\frac{y w_{1} E[x] B}{r}+\frac{y w_{1} B}{r}\right] .
\end{aligned}
$$

The detailed derivation of the expected holding cost $(E[H c])$ is given in Appendix A.

4.7. Inspection Cost per Period. Throughout $t_{2}+t_{3}$, a $100 \%$ inspection process is performed at a rate of $r$ with the aim of 
splitting the perfect-quality items from imperfect-quality items. The company incurs in an inspection cost of $z$ per unit of weight. In consequence, the inspection cost per period is expressed as

$$
Z c=z y w_{1}
$$

4.8. Shortage Cost per Period. During the course of $t_{5}$, the shortages are accumulated till these reach the backordering quantity of $B$ units of weight. The company has a backordering cost for the management of the accumulation of shortages. The backordering cost is computed by multiplying shortage cost $(b)$ per unit of weight per unit of time by area $A_{6}$ (see Figure 5 in Appendix A). Therefore, the backordering cost is calculated as

$$
B c=\frac{b B^{2}}{2 D(s)} .
$$

The detailed derivation of the backordering cost $(B C)$ is specified in Appendix B.

There are several research works that suppose that the carbon emissions generated by the companies are due to the transportation and warehousing activities. But, in fact, there are a lot of operations that emit carbon emissions. For example, the operations involved in the following process also cause carbon emissions: purchasing, setup, feeding, holding inventory, and inspection, among others. It is important to mention that some growing items per se generate carbon emissions (cows, goats, pigs, etc.). The carbon emissions caused by these processes are determined as follows:

\subsection{Carbon Emissions Caused by the Purchasing Action.}

$$
\widehat{P}_{c}=\bar{p} y w_{0} .
$$

4.10. Carbon Emissions Produced by the Setup Activity.

$$
\widehat{S} c=\hat{K} \text {. }
$$

4.11. Carbon Emissions Generated during the Feeding Process.

$$
\begin{aligned}
\widehat{F} \mathcal{c} & =\bar{c} y \int_{0}^{t_{1}} w_{t_{1}}(t) \mathrm{d} t=\hat{c} y \int_{0}^{t_{1}}\left(\frac{\alpha}{1+\beta e^{-\lambda t}}\right) \mathrm{d} t \\
& =\bar{c} y\left(\alpha t_{1}+\frac{\alpha}{\lambda}\left[\ln \left(1+\beta e^{-\lambda t_{1}}\right)-\ln (1+\beta)\right]\right) .
\end{aligned}
$$

4.12. Carbon Emissions Created in Holding Inventory's Operations.

$$
\begin{aligned}
E\left[\hat{H}_{c}\right]= & \hat{h}\left[\frac{y^{2} w_{1}^{2} E\left[(1-x)^{2}\right]}{2 D(s)}-\frac{y w_{1}(1-E[x]) B}{D(s)}\right. \\
& \left.+\frac{B^{2}}{2 D(s)}+\frac{y^{2} w_{1}^{2} E[x]}{r}-\frac{y w_{1} E[x] B}{r}+\frac{y w_{1} B}{r}\right] .
\end{aligned}
$$

4.13. Carbon Emissions Made by the Inspection Process.

$$
\bar{Z}_{c}=\bar{z} y w_{1} .
$$

Carbon $\operatorname{tax}(\theta)$ is one of the well-known mechanisms imposed by government regulations as a penalty. This means that the companies need to pay a tax on the amount of carbon emissions. As a result, the carbon emissions cost per period that the company must pay is

$$
\begin{aligned}
E c= & \theta\left[\bar{p} y w_{0}+\widehat{K}+\bar{z} y w_{1}+\bar{c} y\left(\alpha t_{1}+\frac{\alpha}{\lambda}\left[\ln \left(1+\beta e^{-\lambda t_{1}}\right)-\ln (1+\beta)\right]\right)\right. \\
& \left.+\hat{h}\left[\frac{y^{2} w_{1}^{2} E\left[(1-x)^{2}\right]}{2 D(s)}-\frac{y w_{1}(1-E[x]) B}{D(s)}+\frac{B^{2}}{2 D(s)}+\frac{y^{2} w_{1}^{2} E[x]}{r}-\frac{y w_{1} E[x] B}{r}+\frac{y w_{1} B}{r}\right]\right] .
\end{aligned}
$$

4.14. Expected Total Profit Function. The expected total profit $E[\mathrm{TP}]$ per period is calculated in the following manner: the expected total revenue $E[T R]$ per period minus the expected total cost $E[\mathrm{TC}]$ per period. Basically, the expected total profit $E[\mathrm{TP}]$ is formulated by substituting equations (9) and (12) to (17) and equation (23) into equation (11). Then, the expected total profit $E[\mathrm{TPU}]$ per unit time per period is determined as $E[\mathrm{TPU}]=(E[\mathrm{TP}] / E[T])$. Thus, 


$$
\begin{aligned}
E[\operatorname{TPU}(y, B, s)]= & s D(s)+\frac{v D(s) E[x]}{(1-E[x])}-\frac{p D(s) w_{0}}{w_{1}(1-E[x])}-\frac{K D(s)}{y w_{1}(1-E[x])}-\frac{z D(s)}{(1-E[x])} \\
& -\frac{c D(s)}{w_{1}(1-E[x])}\left[\alpha t_{1}+\frac{\alpha}{\lambda}\left[\ln \left(1+\beta e^{-\lambda t_{1}}\right)-\ln (1+\beta)\right]\right] \\
& -h\left[\frac{y w_{1} E\left[(1-x)^{2}\right]}{2(1-E[x])}-B+\frac{B^{2}}{2 y w_{1}(1-E[x])}+\frac{D(s) y w_{1} E[x]}{r(1-E[x])}+\frac{D(s) B}{r}\right] \\
& -\frac{b B^{2}}{2 y w_{1}(1-E[x])}-\theta\left[\frac{\widehat{p} D(s) w_{0}}{w_{1}(1-E[x])}+\frac{\hat{K} D(s)}{y w_{1}(1-E[x])}+\frac{\bar{z} D(s)}{(1-E[x])}\right. \\
& +\frac{\bar{c} D(s)}{w_{1}(1-E[x])}\left[\alpha t_{1}+\frac{\alpha}{\lambda}\left[\ln \left(1+\beta e^{-\lambda t_{1}}\right)-\ln (1+\beta)\right]\right] \\
& \left.+\bar{h}\left[\frac{y w_{1} E\left[(1-x)^{2}\right]}{2(1-E[x])}-B+\frac{B^{2}}{2 y w_{1}(1-E[x])}+\frac{D(s) y w_{1} E[x]}{r(1-E[x])}+\frac{D(s) B}{r}\right]\right] .
\end{aligned}
$$

Considering that the demand rate depends on selling price with a polynomial function $D(s)=\pi-\rho s^{n}$, the expected total profit $E[\operatorname{TPU}(y, B, s)]$ per unit of time becomes

$$
\begin{aligned}
E[\operatorname{TPU}(y, B, s)]= & s\left(\pi-\rho s^{n}\right)+\frac{v\left(\pi-\rho s^{n}\right) E[x]}{(1-E[x])}-\frac{p\left(\pi-\rho s^{n}\right) w_{0}}{w_{1}(1-E[x])}-\frac{K\left(\pi-\rho s^{n}\right)}{y w_{1}(1-E[x])} \\
& -\frac{z\left(\pi-\rho s^{n}\right)}{(1-E[x])}-\frac{c\left(\pi-\rho s^{n}\right)}{w_{1}(1-E[x])}\left[\alpha t_{1}+\frac{\alpha}{\lambda}\left[\ln \left(1+\beta e^{-\lambda t_{1}}\right)-\ln (1+\beta)\right]\right] \\
& -h\left[\frac{y w_{1} E\left[(1-x)^{2}\right]}{2(1-E[x])}-B+\frac{B^{2}}{2 y w_{1}(1-E[x])}+\frac{\left(\pi-\rho s^{n}\right) y w_{1} E[x]}{r(1-E[x])}+\frac{\left(\pi-\rho s^{n}\right) B}{r}\right] \\
& -\frac{b B^{2}}{2 y w_{1}(1-E[x])}-\theta\left[\frac{\widehat{p}\left(\pi-\rho s^{n}\right) w_{0}}{w_{1}(1-E[x])}+\frac{\widehat{K}\left(\pi-\rho s^{n}\right)}{y w_{1}(1-E[x])}+\frac{\widehat{z}\left(\pi-\rho s^{n}\right)}{(1-E[x])}\right. \\
& +\frac{\bar{c}\left(\pi-\rho s^{n}\right)}{w_{1}(1-E[x])}\left[\alpha t_{1}+\frac{\alpha}{\lambda}\left[\ln \left(1+\beta e^{-\lambda t_{1}}\right)-\ln (1+\beta)\right]\right] \\
& \left.+\hat{h}\left[\frac{y w_{1} E\left[(1-x)^{2}\right]}{2(1-E[x])}-B+\frac{B^{2}}{2 y w_{1}(1-E[x])}+\frac{\left(\pi-\rho s^{n}\right) y w_{1} E[x]}{r(1-E[x])}+\frac{\left(\pi-\rho s^{n}\right) B}{r}\right]\right] .
\end{aligned}
$$

Then, the objective is to maximize the expected total profit $E[T P U(y, B, s)]$ per unit of time. Therefore, the optimization problem is formulated as follows:

$$
\operatorname{Max}_{(y, B, s) \in \Omega} E[\operatorname{TPU}(y, B, s)]
$$

where $\Omega=\left\{(y, B, s): y>0,0 \leq B \leq y w_{1}\right.$ and $\left.p \leq s \leq\left(\frac{\pi}{\rho}\right)^{(1 / n)}\right\}$.
It is important to remark that the abovementioned maximization formulation is a nonlinear optimization problem.

\section{Solution Procedure}

Firstly, the unconstrained optimization problem is considered in order to obtain some theoretical results. Secondly, an algorithm for finding the optimal solution to the constrained problem given by equation (26) is developed. 
5.1. Theoretical Results. The aim is to find the optimal values for order quantity $(y)$, backordering quantity $(B)$, and selling price $(s)$ that maximize the expected total profit per unit of time. As the expected total profit per unit of time function $E[\operatorname{TPU}(y, B, s)]$ is continuous and twice differentiable with respect to the three decision variables $(y, B, s)$ on the interval $[0, \infty]$, there exists a global maximum on that interval.
The necessary conditions which must be satisfied for the optimality of solution that maximizes the expected total profit per unit of time function are $((\partial E[\operatorname{TPU}(y, B, s)]) / \partial y)=0, \quad(\partial E[\operatorname{TPU}(y, B, s)] / \partial B)=0$, and $((\partial E[\operatorname{TPU}(y, B, s)]) / \partial s)=0$.

The first partial derivative of $E[\operatorname{TPU}(y, B, s)]$ given in equation (25) with respect to $y$ is expressed as follows:

$$
\begin{aligned}
\frac{\partial E[\operatorname{TPU}(y, B, s)]}{\partial y}= & \frac{K\left(\pi-\rho s^{n}\right)}{y^{2} w_{1}(1-E[x])} \\
& -h\left[\frac{w_{1} E\left[(1-x)^{2}\right]}{2(1-E[x])}-\frac{B^{2}}{2 y^{2} w_{1}(1-E[x])}+\frac{\left(\pi-\rho s^{n}\right) w_{1} E[x]}{r(1-E[x])}\right]+\frac{b B^{2}}{2 y^{2} w_{1}(1-E[x])} \\
& -\theta\left[-\frac{\widehat{K}\left(\pi-\rho s^{n}\right)}{y^{2} w_{1}(1-E[x])}+\hat{h}\left[\frac{w_{1} E\left[(1-x)^{2}\right]}{2(1-E[x])}-\frac{B^{2}}{2 y^{2} w_{1}(1-E[x])}+\frac{\left(\pi-\rho s^{n}\right) w_{1} E[x]}{r(1-E[x])}\right]\right]=0 .
\end{aligned}
$$

The first partial derivative of $\operatorname{E}[\operatorname{TPU}(y, B, s)]$ with respect to $B$ is given by

$$
\begin{aligned}
\frac{\partial[\operatorname{TPU}(y, B, s)]}{\partial B}= & -h\left[-1+\frac{B}{y w_{1}(1-E[x])}+\frac{\left(\pi-\rho s^{n}\right)}{r}\right]-\frac{b B}{y w_{1}(1-E[x])} \\
& -\theta \hat{h}\left[-1+\frac{B}{y w_{1}(1-E[x])}+\frac{\left(\pi-\rho s^{n}\right)}{r}\right]=0 .
\end{aligned}
$$

The first partial derivative of $E[\operatorname{TPU}(y, B, s)]$ with respect to $s$ is

$$
\begin{aligned}
\frac{\partial E[\operatorname{TPU}(y, B, s)]}{\partial s}= & \pi-(n+1) \rho s^{n}-\frac{\rho n s^{n-1}}{w_{1}(1-E[x])}\left[v E[x] w_{1}-(p+\theta \bar{p}) w_{0}-\frac{(K+\theta \widehat{K})}{y}\right. \\
& -(z+\theta \bar{z}) w_{1}-(c+\theta \bar{c})\left[\alpha t_{1}+\frac{\alpha}{\lambda}\left[\ln \left(1+\beta e^{-\lambda t_{1}}\right)-\ln (1+\beta)\right]\right] \\
& \left.-\frac{(h+\theta \hat{h})}{r}\left[y w_{1}^{2} E[x]+B w_{1}(1-E[x])\right]\right]=0 .
\end{aligned}
$$

By solving equations (27) and (28) simultaneously for the decision variables $y$ and $B$, one has

$$
\begin{aligned}
& y=\sqrt{\frac{2\left(\pi-\rho s^{n}\right) r(K+\theta \hat{K})}{w_{1}^{2}(h+\theta \hat{h})\left[r E\left[(1-x)^{2}\right]+2\left(\pi-\rho s^{n}\right) E[x]\right]-\left(\left[(h+\theta \hat{h}) w_{1}(1-E[x])\left[r-\left(\pi-\rho s^{n}\right)\right]\right]^{2} /((h+b+\theta \hat{h}) r)\right)}}, \\
& B=\frac{(h+\theta \hat{h}) y w_{1}(1-E[x])\left[r-\left(\pi-\rho s^{n}\right)\right]}{(h+b+\theta \hat{h}) r} .
\end{aligned}
$$


The sufficient conditions for the optimality of the solution that maximize $E[\operatorname{TPU}(y, B, s)]$ are given in Appendix C.

5.2. Algorithm for Finding the Optimal Solution. The following Algorithm 1 is proposed taking into account the theoretical results and constrains.

5.3. Special Cases. The proposed inventory model developed in this research work is a general inventory model because it contains the following inventory models as special cases: Sebatjane and Adetunji's [40] improved inventory model, Maddah and Jaber [11], Chang and Ho [13], Shih [61], Silver [62], and the traditional EOQ inventory models with and without shortages.

(i) When $n=1$, it means that the product has a linear price-dependent demand $(\pi-\rho s)$. It is expressed as follows:

$$
\begin{aligned}
& y=\sqrt{\frac{2(\pi-\rho s) r(K+\theta \hat{K})}{w_{1}^{2}(h+\theta \hat{h})\left[r E\left[(1-x)^{2}\right]+2(\pi-\rho s) E[x]\right]-\left(\left[(h+\theta \hat{h}) w_{1}(1-E[x])[r-(\pi-\rho s)]\right]^{2} /((h+b+\theta \hat{h}) r)\right)}}, \\
& B=\frac{(h+\theta \hat{h}) y w_{1}(1-E[x])[r-(\pi-\rho s)]}{(h+b+\theta \hat{h}) r}, \\
& \pi-2 \rho s-\frac{\rho}{w_{1}(1-E[x])\left[v E[x] w_{1}-(p+\theta \widehat{p}) w_{0}-\frac{(K+\theta \hat{K})}{y}-(z+\theta \bar{z}) w_{1}\right.} \\
& \left.-(c+\theta \widehat{c})\left[\alpha t_{1}+\frac{\alpha}{\lambda}\left[\ln \left(1+\beta e^{-\lambda t_{1}}\right)-\ln (1+\beta)\right]\right]-\frac{(h+\theta \hat{h})}{r}\left[y w_{1}^{2} E[x]+B w_{1}(1-E[x])\right]\right]=0 .
\end{aligned}
$$

(ii) When shortages and carbon tax rate are not considered and the demand is not dependent on price (i.e., $b \longrightarrow \infty, \theta \longrightarrow 0$ and $\rho \longrightarrow 0$ ), then an improved version of Sebatjane and Adetunji's [40] inventory model is obtained. It is shown as follows:

$$
y=\sqrt{\frac{2 \pi K}{h w_{1}^{2}\left[E\left[(1-x)^{2}\right]+((2 \pi E[x]) / r)\right]}} .
$$

(iii) When shortages are permitted, carbon tax rate is not involved, the demand is not dependent on price, and the products are not of the type of growing items, and thus, the feeding process is not incorporated (i.e., $b>0, \theta \longrightarrow 0, \rho \longrightarrow 0$, and $c \longrightarrow 0$ ), and then, the inventory model of Chang and Ho [13] is determined. It is given by

$$
\begin{aligned}
y & =\sqrt{\frac{2 \pi K}{h\left[E\left[(1-x)^{2}\right]+((2 \pi E[x]) / r)\right]-\left([h(1-E[x])]^{2} /(h+b)\right)}}, \\
B & =\frac{h y(1-E[x])}{(h+b)} .
\end{aligned}
$$

(iv) When shortages are not allowed, carbon tax rate is not taken account, the demand is not dependent on price, and the products are not of the type of growing items $(b \longrightarrow \infty, \theta \longrightarrow 0, \rho \longrightarrow 0$, and $c \longrightarrow 0)$; then, Maddah and Jaber's [11] inventory model is derived. It is presented as follows:

$$
y=\sqrt{\frac{2 \pi K}{h\left[E\left[(1-x)^{2}\right]+((2 \pi E[x]) / r)\right]}} .
$$

(v) When shortages are not tolerable, carbon tax rate is not considered, the demand does not depend on price, the goods are not of the type of growing 
Step 1. Provide the input parameters of the inventory system.

Step 2. Compute the selling price $\left(s^{\prime}\right)$, the order quantity $\left(y^{\prime}\right)$, and the backordering quantity $\left(B^{\prime}\right)$ by solving simultaneously equations (29)-(31).

Step 3. If the optimality conditions are satisfied, then go to Step 4. Else, go to Step 8 .

Step 4. If $p \leq s \leq(\pi / \rho)^{(1 / n)}$, then go to Step 7. Else, go to Step 5 .

Step 5. If $s>(\pi / \rho)^{(1 / n)}$, then set $s^{\prime}=(\pi / \rho)^{(1 / n)}$, determine the order quantity $\left(y^{\prime}\right)$ with equation (30) and the backordering quantity $\left(B^{\prime}\right)$ with equation (31), and go to Step 6. Else, set $s^{\prime}=p$ and calculate the order quantity $\left(y^{\prime}\right)$ with equation (30) and the backordering quantity $\left(B^{\prime}\right)$ with equation $(31)$ and go to Step 6.

Step 6. Calculate the expected total profit per unit of time $E\left[\mathrm{TPU}\left(y^{\prime}, B^{\prime}, s^{\prime}\right)\right]$ with equation (25).

Step 7. Report the solution: $\left(y^{*}, B^{*}, s^{*}\right)=\left(y^{\prime}, B^{\prime}, s^{\prime}\right)$ and $E\left[\operatorname{TPU}^{*}\left(y^{*}, B^{*}, s^{*}\right)\right]=E\left[\operatorname{TPU}\left(y^{\prime}, B^{\prime}, s^{\prime}\right)\right]$.

Step 8. Stop.

Algorithm 1: Algorithm to find the optimal solution.

items, and inspection rate is sufficiently large (i.e., $b \longrightarrow \infty, \theta \longrightarrow 0, \rho \longrightarrow 0, c \longrightarrow 0$ and $r \longrightarrow \infty)$; then, it is converted to the inventory model of Shih [61] and Silver [62]. It is expressed as

$$
y=\sqrt{\frac{2 \pi K}{h\left[E\left[(1-x)^{2}\right]\right]}} .
$$

(vi) When shortages are permissible, carbon tax rate is not incorporated, the demand is not dependent on price, the products are not of the type of growing items, and the products are of perfect quality (i.e., $b>0, \theta \longrightarrow 0, \rho \longrightarrow 0, c \longrightarrow 0$, and $x=0$ ); then, the traditional inventory model with shortages and with full backordering is found. It is written as follows:

$$
\begin{aligned}
& y=\sqrt{\frac{2 \pi K}{h}} \sqrt{\frac{h+b}{b}}, \\
& B=\frac{h y}{(h+b)} .
\end{aligned}
$$

(vii) When shortages are not allowable, carbon tax rate is not taken into consideration, the demand does not depend on price, the goods are not of type of growing items, and these are of good quality (i.e., $b \longrightarrow \infty, \theta \longrightarrow 0, \rho \longrightarrow 0, c \longrightarrow 0$, and $x=0)$; then, it is transformed to the traditional inventory model without shortages proposed by Harris [1]. It is

$$
y=\sqrt{\frac{2 \pi K}{h}} .
$$

It is important to remark that the inventory model developed in this research does not reduce to Salameh and Jaber's [8] and Wee et al.'s [10] inventory models because those inventory models contain a flaw that was identified and corrected by Maddah and Jaber [11] and Chang and Ho [13], respectively. Basically, Maddah and Jaber [11] and Chang and Ho [13] proposed improved versions for Salameh and Jaber's [8] and Wee et al.'s [10] inventory models, respectively. For this reason, the proposed inventory model developed in this research work, in fact, converges to Maddah and Jaber's [11] and Chang and Ho's [13] inventory models as it was mentioned above.

\section{Numerical Examples}

This section presents and solves some numerical examples in order to illustrate the applicability of the proposed inventory model.

Example 1. This example considers the input parameters of Sebatjane and Adetunji [40]. To solve this inventory problem, it is stated $b \longrightarrow \infty, \theta \longrightarrow 0$, and $\rho \longrightarrow 0$. The values for the data are $\pi=1000000, \rho=0, \theta=0, s=0.05$ $\mathrm{ZAR} / \mathrm{g}, v=0.02 \mathrm{ZAR} / \mathrm{g}, K=1000 \mathrm{ZAR} /$ cycle, $h=0.04 \mathrm{ZAR} /$ g/year, $c=0.2 \mathrm{ZAR} / \mathrm{g}, p=0.025 \mathrm{ZAR} / \mathrm{g}, z=0.00025 \mathrm{ZAR} /$ g, $\quad r=5256000 \mathrm{~g} /$ year, $\quad \alpha=6870 \mathrm{~g}, \quad \beta=120 \lambda=40 /$ year, $w_{0}=57 \mathrm{~g}$, and $w_{1}=1500 \mathrm{~g}$, and the percentage of imperfect growing items follows a uniform distribution $(x \sim U[\gamma, \delta])$ with the probability density function $g(x)$ which is given as follows:

$$
x \sim g(x)= \begin{cases}\frac{1}{\delta-\gamma}, & \gamma \leq x \leq \delta \\ 0, & \text { otherwise }\end{cases}
$$

Considering $x \sim U[0,0.04]$,

$$
x \sim g(x)= \begin{cases}25, & 0 \leq x \leq 0.04 \\ 0, & \text { otherwise. }\end{cases}
$$

Then, $E[x]$ and $E\left[(1-x)^{2}\right]$ are computed as follows: 


$$
\begin{gathered}
E[x]=\int_{\gamma}^{\delta} x f(x) \mathrm{d} x=\frac{\gamma+\delta}{2}=\frac{0+0.04}{2}=0.02, \\
E\left[(1-x)^{2}\right]=\int_{\gamma}^{\delta}(1-x)^{2} f(x) \mathrm{d} x=\frac{\gamma^{2}+\gamma \delta+\delta^{2}}{3}+1-\gamma-\delta, \\
E\left[(1-x)^{2}\right]=\frac{0^{2}+0(0.04)+(0.04)^{2}}{3}+1-0-0.04=0.960533333 .
\end{gathered}
$$

As it was mentioned before, the proposed inventory model generates an improved version of Sebatjane and Adetunji's [40] inventory model. Additionally, the proposed inventory model also can be used for optimizing the order quantity $(y)$ and backordering quantity $(B)$ when the selling price $(s)$ is given. Obviously, it also optimizes the three decision variables $(y, B, s)$. Therefore, the numerical example is solved for different values of $\delta$ for the four inventory models: (I) Sebatjane and Adetunji [40] (original version), (II) Sebatjane and Adetunji [40] (improved version), (III) the proposed inventory model when selling price $(s)$ is given, and (IV) the proposed inventory model when the selling price $(s)$ is optimized. Table 2 shows the comparison of the optimal solutions among the four inventory models.

From Table 2, it is observed that the expected total profit of both the proposed inventory models (see columns III and IV) is greater than that of Sebatjane and Adetunji's [40] inventory models (see columns I and II).

Example 2. This example uses the input parameters of Wee et al. [10] and Chang and Ho [13]. To solve this inventory system, the following is established: $b>0, \theta \longrightarrow 0, \rho \longrightarrow 0$, and $c \longrightarrow 0$. The data are as follows: $\pi=50000, \rho=0, \theta=0, c=0$, $s=50 \$ /$ unit, $v=20 \$ /$ unit, $K=100 \$ /$ cycle, $h=5 \$ /$ unit/year, $b=10 \$ /$ unit/year $\quad p=25 \$ /$ unit, $\quad z=0.5 \$ /$ unit, $r=175200 u$ units/year, and $x \sim U[0,0.04]$. The optimal solution is as follows: $E\left[\operatorname{TPU}^{*}\left(y^{*}, B^{*}\right)\right]=1213562 \$ /$ year, $y^{*}=1751.671$ units, and $B^{*}=572.2127$ units. This solution is the same as in the work of Chang and Ho [13].

Example 3. Now, let us consider some dataset of Sebatjane and Adetunji [40] which is $v=0.02 \mathrm{ZAR} / \mathrm{g}$, $K=1000 \mathrm{ZAR} /$ cycle $, \quad c=0.2 \mathrm{ZAR} / \mathrm{g}, \quad p=0.025 \mathrm{ZAR} / \mathrm{g}$, $z=0.00025 \mathrm{ZAR} / \mathrm{g}, r=5256000 \mathrm{~g} /$ year $, \alpha=6870 \mathrm{~g}, \beta=120$, $\lambda=40 /$ year, $w_{0}=57 \mathrm{~g}, w_{1}=1500 \mathrm{~g}$, and $x \sim U[0,0.04]$. Here, the holding cost is $h=0.2 \mathrm{ZAR} / \mathrm{g} /$ year. For the implementation of the proposed inventory model, additional information is required. These data are related to the type of the demand function dependent on the price, the backordering cost, and carbon emissions. Therefore, it is necessary to state the following data: Assume that the demand rate of the growing items follows a polynomial function given by $D(s)=\pi-\rho s^{n}$ with values of $\pi=135000$, $\rho=1050$, and $n=2$. The backordering cost is $b=0.1 \mathrm{ZAR} /$ $\mathrm{g} /$ year. The relevant input parameters related to carbon emissions are $\theta=0.0045 \mathrm{ZAR} /$ tons, $\widehat{K}=2000$ tons/year, $\widehat{h}=0.2$ tons/year, $\widehat{c}=0.65$ tons/year, $\bar{p}=0.375$ tons/year, and $\bar{z}=0.005$ tons/year. By applying the proposed algorithm, the optimal solution is obtained: $E\left[T P U^{*}\left(y^{*}\right.\right.$, $\left.\left.B^{*}, s^{*}\right)\right]=584997.4 \quad \mathrm{ZAR} /$ year, $y^{*}=34.26474$ units of newborn growing items, $B^{*}=33054.63 \mathrm{~g}$, and $s^{*}=6$ $.555838 \mathrm{ZAR} / \mathrm{g}$. Figures 2-4 demonstrate graphically the concavity property of the expected total profit with respect to pairs of decision variables $y$ and $B$; $y$ and $s$; and $B$ and $s$, respectively.

\section{Sensitivity Analysis}

This section provides a sensitivity analysis in order to investigate the effects of changing the input parameters on the expected total profit per unit of time $\left(E\left[\mathrm{TPU}^{*}\right]\right)$, order quantity $\left(y^{*}\right)$, backordering quantity $\left(B^{*}\right)$, and selling price $\left(s^{*}\right)$ of the growing items. The sensitivity analysis is performed taking into consideration the data of Example 3 when only one parameter changes at a time and other parameters are kept at their original values. Specifically, the sensitivity analysis is performed to study the effect of scale, sensitivity and power index demand parameters, selling price and expected value of a percent of poorer-quality growing items, setup cost, holding cost, backordering cost, feeding cost, purchasing cost, inspection cost, carbon tax rate, and the amount of carbon emissions caused by the operations of the processes in ordering, holding, feeding, purchasing, and screening. The results of the sensitivity analysis are given in Tables 3-5. Based on the behavioral changes as reflected in Tables 3-5, the following observations are made:

(1) The value of $E\left[\mathrm{TPU}^{*}\right]$ is highly sensitive to the demand parameters $\pi, \rho, n$ and less sensitive to other parameters. On the one hand, the higher the value of the scale parameter of demand $\pi$, the higher the value of $E\left[\mathrm{TPU}^{*}\right]$ due to the fact that demand increases; therefore, the sales increase, and this leads to high profits. For this reason, it is suggested for the manager to apply advertising actions in order to boost the demand. On the other hand, when the sensitivity parameter of the demand $\rho$ grows, the $E\left[\mathrm{TPU}^{*}\right]$ declines because this parameter has a negative impact on the demand, making it drop. For this reason, it is advisable for the decision maker to 
TABLe 2: A comparison of the optimal solutions of the four inventory models.

\begin{tabular}{|c|c|c|c|c|c|c|c|c|c|c|c|c|c|}
\hline \multirow[b]{3}{*}{$\gamma$} & \multirow[b]{3}{*}{$\delta$} & \multirow[b]{3}{*}{$E[x]$} & \multicolumn{2}{|c|}{ I } & \multicolumn{2}{|c|}{ II } & \multicolumn{3}{|c|}{ III } & \multicolumn{4}{|c|}{ IV } \\
\hline & & & $\begin{array}{r}\text { Sebatja } \\
\text { Adetu } \\
\text { (orig } \\
b \mathrm{o} \\
\rho\end{array}$ & $\begin{array}{l}\text { ne and } \\
\text { nji [40] } \\
\text { inal), } \\
o, \theta=0 \text {, } \\
=0\end{array}$ & $\begin{array}{r}\text { Sebatja } \\
\text { Adetu } \\
\text { (imp } \\
\text { inventor } \\
b \longrightarrow 0 \\
\rho\end{array}$ & $\begin{array}{l}\text { ne and } \\
\text { nji [40] } \\
\text { roved } \\
\text { y model), } \\
0, \theta=0 \\
=0\end{array}$ & \multicolumn{3}{|c|}{$\begin{array}{l}\text { The proposed inventory model, } \\
\qquad \rho=0, s=0.05\end{array}$} & \multicolumn{4}{|c|}{ The proposed inventory model, $\rho=700000$} \\
\hline & & & $y^{*}$ & $E\left[\mathrm{TPU}^{*}\right]$ & $y^{*}$ & $E\left[\mathrm{TPU}^{*}\right]$ & $y^{*}$ & $B^{*}$ & $E\left[\mathrm{TPU}^{*}\right]$ & $y^{*}$ & $B^{*}$ & $s^{*}$ & $E\left[\mathrm{TPU}^{*}\right]$ \\
\hline 0 & 0.04 & 0.02 & 151.5143 & 34641.73 & 151.5039 & 34641.11 & 167.9070 & 57103.70 & 35518.41 & 138.9623 & 51818.67 & 0.6940517 & 449132.6 \\
\hline 0 & 0.10 & 0.05 & 155.2887 & 35013.46 & 155.2186 & 35009.38 & 171.7566 & 56624.78 & 35880.02 & 142.5000 & 51509.93 & 0.6939366 & 449374.6 \\
\hline 0 & 0.20 & 0.10 & 161.8760 & 35680.21 & 161.5588 & 35662.24 & 178.2198 & 55663.16 & 36519.49 & 148.5423 & 50865.87 & 0.6937328 & 449801.7 \\
\hline 0 & 0.30 & 0.15 & 168.8356 & 36413.78 & 168.0293 & 36369.20 & 184.6550 & 54469.01 & 37209.73 & 154.7091 & 50032.07 & 0.6935122 & 450261.3 \\
\hline 0 & 0.40 & 0.20 & 176.1594 & 37225.05 & 174.5420 & 37137.38 & 190.9380 & 53009.26 & 37957.34 & 160.9085 & 48973.44 & 0.6932723 & 450757.0 \\
\hline 0 & 0.50 & 0.25 & 183.8244 & 38127.53 & 180.9801 & 37975.53 & 196.9174 & 51252.47 & 38770.55 & 167.0178 & 47653.14 & 0.6930098 & 451293.2 \\
\hline
\end{tabular}

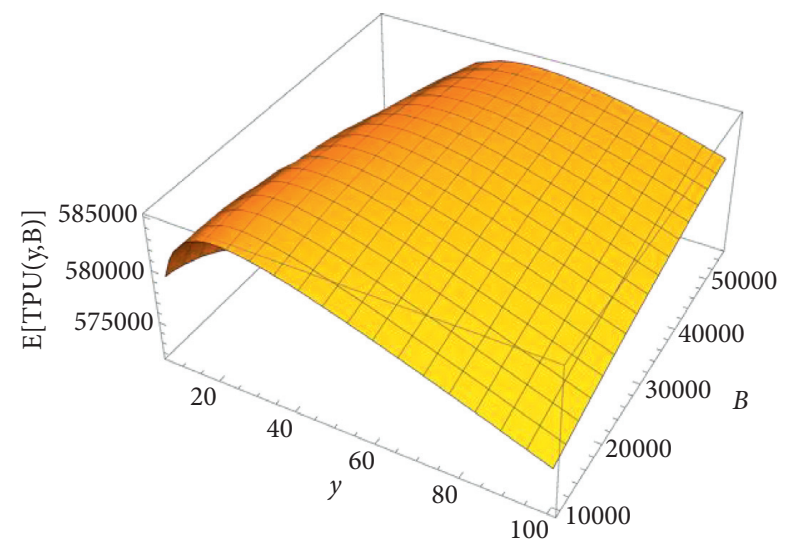

Figure 2: Concavity of $E[\operatorname{TPU}(y, B)]$ w.r.t. $y, B$

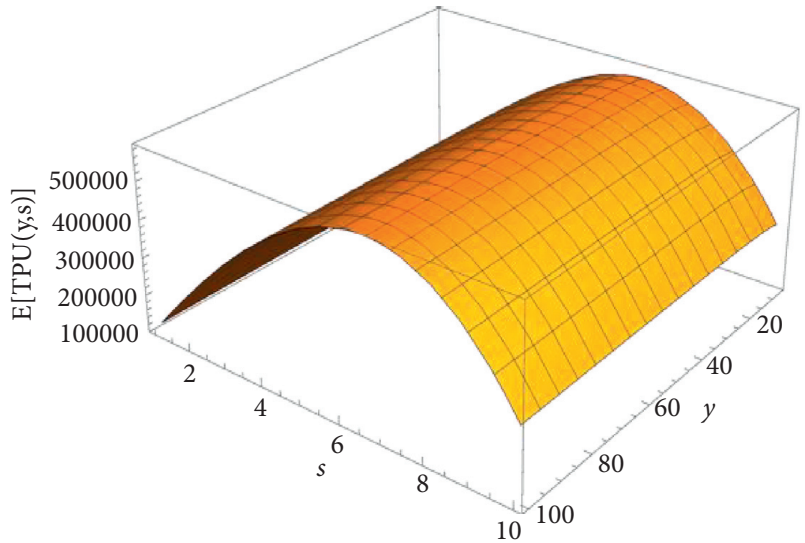

FIgURe 3: Concavity of $E[\operatorname{TPU}(y, s)]$ w.r.t. $y, s$

reduce the selling price. However, a higher value of $K$ induces higher values of $s$ but a lower value for $E\left[\mathrm{TPU}^{*}\right]$. This means that as the setup cost increases, the company must raise selling price $s$.

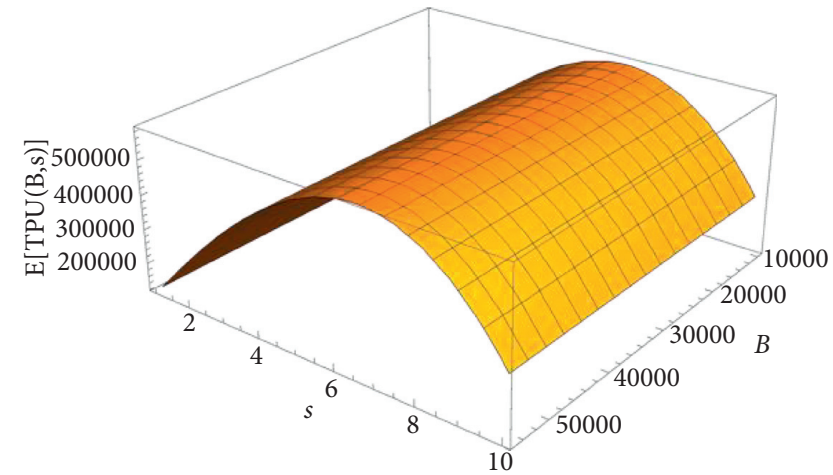

Figure 4: Concavity of $E[\operatorname{TPU}(B, s)]$ w.r.t. $B, s$

(2) The value of $y$ is more sensitive to the parameters $\pi, n, K, h, b$ and less sensitive to other parameters. The higher the value of the parameter $b$, the smaller the value of $y$.

(3) The value of $B$ is more sensitive to the parameters $\pi, n, K, h, b$ and less sensitive to other parameters. The higher the value of $b$, the smaller the value of $B$. 
TABLE 3: Effects of the demand parameters $(\pi, \rho, n)$, the price of imperfect growing items $(v)$, and the percent of the imperfect growing items $(E[x])$ on the optimal solution.

\begin{tabular}{|c|c|c|c|c|c|}
\hline Parameter & Value & $y^{*}$ & $B^{*}$ & $s^{*}$ & $E\left[\mathrm{TPU}^{*}\right]$ \\
\hline \multirow{5}{*}{$\pi$} & 85000 & 27.51468 & 26714.18 & 5.205486 & 291168.5 \\
\hline & 135000 & 34.26474 & 33054.63 & 6.555838 & 584997.4 \\
\hline & 185000 & 39.64369 & 37996.92 & 7.672019 & 940097.9 \\
\hline & 235000 & 44.17254 & 42062.76 & 8.645232 & 1347288 \\
\hline & 285000 & 48.10619 & 45509.16 & 9.519438 & 1800598 \\
\hline \multirow{5}{*}{$\rho$} & 650 & 34.26961 & 33059.16 & 8.329802 & 744653.9 \\
\hline & 750 & 34.26828 & 33057.92 & 7.755266 & 692945.8 \\
\hline & 850 & 34.26703 & 33056.76 & 7.285369 & 650655.1 \\
\hline & 950 & 34.26586 & 33055.67 & 6.891773 & 615231.4 \\
\hline & 1050 & 34.26474 & 33054.63 & 6.555838 & 584997.4 \\
\hline \multirow{5}{*}{$n$} & 2 & 34.26474 & 33054.63 & 6.555838 & 584997.4 \\
\hline & 5 & 37.98523 & 36485.12 & 1.850223 & 202864.7 \\
\hline & 7 & 38.84940 & 37274.30 & 1.490172 & 170704.7 \\
\hline & 10 & 39.54134 & 37903.96 & 1.281047 & 151875.7 \\
\hline & 14 & 40.02588 & 38343.67 & 1.167557 & 141757.1 \\
\hline \multirow{5}{*}{$v$} & 0.02 & 34.26474 & 33054.63 & 6.555838 & 584997.4 \\
\hline & 0.06 & 34.26541 & 33055.26 & 6.555565 & 585070.7 \\
\hline & 0.10 & 34.26608 & 33055.88 & 6.555293 & 585144.1 \\
\hline & 0.14 & 34.26675 & 33056.50 & 6.555020 & 585217.5 \\
\hline & 0.18 & 34.26742 & 33057.12 & 6.554748 & 585290.8 \\
\hline \multirow{5}{*}{$E[x]$} & 0.01 & 33.94088 & 33076.32 & 6.555872 & 584987.5 \\
\hline & 0.02 & 34.26474 & 33054.63 & 6.555838 & 584997.4 \\
\hline & 0.03 & 34.59095 & 33028.81 & 6.555804 & 585007.0 \\
\hline & 0.04 & 34.91934 & 32998.64 & 6.555770 & 585016.4 \\
\hline & 0.05 & 35.24975 & 32963.88 & 6.555736 & 585025.6 \\
\hline
\end{tabular}

TABLE 4: Impacts of the costs of the inventory system $(K, h, b, c, p, z, \theta)$ on the optimal solution.

\begin{tabular}{|c|c|c|c|c|c|}
\hline Parameter & Value & $y^{*}$ & $B^{*}$ & $s^{*}$ & $E\left[\mathrm{TPU}^{*}\right]$ \\
\hline \multirow{5}{*}{ K } & 1000 & 34.26474 & 33054.63 & 6.555838 & 584997.4 \\
\hline & 1200 & 37.50542 & 36180.93 & 6.556512 & 584656.6 \\
\hline & 1400 & 40.48714 & 39057.41 & 6.557133 & 584343.1 \\
\hline & 1600 & 43.26350 & 41735.80 & 6.557711 & 584051.2 \\
\hline & 1800 & 45.87182 & 44252.08 & 6.558254 & 583776.9 \\
\hline \multirow{5}{*}{$h$} & 0.12 & 38.34897 & 30325.67 & 6.554933 & 585380.6 \\
\hline & 0.16 & 35.88691 & 31977.51 & 6.555439 & 585160.0 \\
\hline & 0.2 & 34.26474 & 33054.63 & 6.555838 & 584997.4 \\
\hline & 0.24 & 33.09099 & 33786.80 & 6.556172 & 584869.7 \\
\hline & 0.28 & 32.18620 & 34295.59 & 6.556464 & 584765.0 \\
\hline \multirow{5}{*}{$b$} & 0.1 & 34.26474 & 33054.63 & 6.555838 & 584997.4 \\
\hline & 0.15 & 30.54445 & 25267.19 & 6.556552 & 584559.0 \\
\hline & 0.2 & 28.43147 & 20585.99 & 6.557049 & 584259.0 \\
\hline & 0.25 & 27.05971 & 17420.14 & 6.557416 & 584039.2 \\
\hline & 0.3 & 26.09415 & 15121.73 & 6.557700 & 583870.6 \\
\hline \multirow{5}{*}{$c$} & 0.05 & 34.26816 & 33057.81 & 6.554445 & 585372.3 \\
\hline & 0.1 & 34.26702 & 33056.75 & 6.554909 & 585247.3 \\
\hline & 0.15 & 34.26588 & 33055.69 & 6.555374 & 585122.3 \\
\hline & 0.2 & 34.26474 & 33054.63 & 6.555838 & 584997.4 \\
\hline & 0.25 & 34.26360 & 33053.58 & 6.556302 & 584872.4 \\
\hline \multirow{5}{*}{$p$} & 0.025 & 34.26474 & 33054.63 & 6.555838 & 584997.4 \\
\hline & 0.05 & 34.26395 & 33053.90 & 6.556162 & 584910.2 \\
\hline & 0.075 & 34.26315 & 33053.16 & 6.556485 & 584823.1 \\
\hline & 0.1 & 34.26236 & 33052.42 & 6.556809 & 584736.0 \\
\hline & 0.125 & 34.26156 & 33051.68 & 6.557133 & 584648.9 \\
\hline \multirow{5}{*}{$z$} & 0.00025 & 34.26474 & 33054.63 & 6.555838 & 584997.4 \\
\hline & 0.0005 & 34.26453 & 33054.44 & 6.555923 & 584974.4 \\
\hline & 0.00075 & 34.26432 & 33054.25 & 6.556008 & 584951.5 \\
\hline & 0.001 & 34.26412 & 33054.05 & 6.556094 & 584928.6 \\
\hline & 0.00125 & 34.26391 & 33053.86 & 6.556179 & 584905.6 \\
\hline
\end{tabular}


TABLE 4: Continued.

\begin{tabular}{lcccrr}
\hline Parameter & Value & $y^{*}$ & $B^{*}$ & $s^{*}$ & $E\left[\mathrm{TPU}^{*}\right]$ \\
\hline \multirow{4}{*}{$\theta$} & 0.0045 & 34.26474 & 33054.63 & 6.555838 & 584997.4 \\
& 0.01 & 34.41339 & 33258.23 & 6.555956 & 584955.2 \\
& 0.0155 & 34.56096 & 33460.86 & 6.556074 & 584913.2 \\
& 0.021 & 34.70746 & 33662.55 & 6.556192 & 584871.2 \\
& 0.0265 & 34.85293 & 33863.29 & 6.556309 & 584829.3 \\
\hline
\end{tabular}

TABLE 5: Impacts of the carbon emission parameters $(\widehat{K}, \widehat{h}, \widehat{c}, \widehat{p}, \widehat{z})$ on the optimal solution.

\begin{tabular}{|c|c|c|c|c|c|}
\hline Parameter & Value & $y^{*}$ & $B^{*}$ & $s^{*}$ & $E\left[\mathrm{TPU}^{*}\right]$ \\
\hline \multirow{5}{*}{$\hat{K}$} & 2000 & 34.26474 & 33054.63 & 6.555838 & 584997.4 \\
\hline & 2500 & 34.30291 & 33091.45 & 6.555846 & 584993.3 \\
\hline & 3000 & 34.34103 & 33128.23 & 6.555854 & 584989.3 \\
\hline & 3500 & 34.37910 & 33164.96 & 6.555862 & 584985.3 \\
\hline & 4000 & 34.41714 & 33201.65 & 6.555870 & 584981.3 \\
\hline \multirow{5}{*}{$\widehat{h}$} & 0.2 & 34.26474 & 33054.63 & 6.555838 & 584997.4 \\
\hline & 0.4 & 34.23432 & 33074.31 & 6.555846 & 584994.2 \\
\hline & 0.6 & 34.20411 & 33093.81 & 6.555854 & 584991.0 \\
\hline & 0.8 & 34.17412 & 33113.15 & 6.555862 & 584987.8 \\
\hline & 1 & 34.14434 & 33132.32 & 6.555870 & 584984.7 \\
\hline \multirow{5}{*}{$\widehat{c}$} & 0.65 & 34.26474 & 33054.63 & 6.555838 & 584997.4 \\
\hline & 1.3 & 34.26468 & 33054.57 & 6.555865 & 584990.0 \\
\hline & 1.95 & 34.26461 & 33054.51 & 6.555892 & 584982.7 \\
\hline & 2.6 & 34.26454 & 33054.45 & 6.555919 & 584975.4 \\
\hline & 3.25 & 34.26448 & 33054.39 & 6.555947 & 584968.1 \\
\hline \multirow{5}{*}{$\widehat{p}$} & 0.375 & 34.26474 & 33054.63 & 6.555838 & 584997.4 \\
\hline & 0.75 & 34.26469 & 33054.58 & 6.555860 & 584991.5 \\
\hline & 1.125 & 34.26464 & 33054.53 & 6.555882 & 584985.6 \\
\hline & 1.5 & 34.26458 & 33054.48 & 6.555904 & 584979.7 \\
\hline & 1.875 & 34.26453 & 33054.44 & 6.555925 & 584973.8 \\
\hline \multirow{5}{*}{$\bar{z}$} & 0.005 & 34.26474 & 33054.63 & 6.555838 & 584997.4 \\
\hline & 0.015 & 34.26470 & 33054.60 & 6.555853 & 584993.2 \\
\hline & 0.025 & 34.26467 & 33054.56 & 6.555869 & 584989.1 \\
\hline & 0.035 & 34.26463 & 33054.53 & 6.555884 & 584985.0 \\
\hline & 0.045 & 34.26459 & 33054.49 & 6.555899 & 584980.8 \\
\hline
\end{tabular}

TABLE 6: Sensitivity analysis of the key parameters of the inventory system.

\begin{tabular}{lcccc}
\hline Parameter & $y^{*}$ & $B^{*}$ & $s^{*}$ & $E\left[\mathrm{TPU}^{*}\right]$ \\
\hline$\pi \uparrow$ & $\uparrow$ & $\uparrow$ & $\uparrow$ & $\uparrow$ \\
$\rho \uparrow$ & $\downarrow$ & $\downarrow$ & $\downarrow$ & $\downarrow$ \\
$n \uparrow$ & $\uparrow$ & $\uparrow$ & $\downarrow$ & $\downarrow$ \\
$v \uparrow$ & $\uparrow$ & $\uparrow$ & $\downarrow$ & $\uparrow$ \\
$K \uparrow$ & $\uparrow$ & $\uparrow$ & $\uparrow$ & $\downarrow$ \\
$h \uparrow$ & $\downarrow$ & $\uparrow$ & $\uparrow$ & $\downarrow$ \\
$b \uparrow$ & $\downarrow$ & $\downarrow$ & $\uparrow$ & $\downarrow$ \\
$c \uparrow$ & $\downarrow$ & $\downarrow$ & $\uparrow$ & $\downarrow$ \\
$p \uparrow$ & $\downarrow$ & $\downarrow$ & $\uparrow$ & $\downarrow$ \\
$z \uparrow$ & $\downarrow$ & $\downarrow$ & $\uparrow$ & $\downarrow$ \\
$\theta \uparrow$ & $\uparrow$ & $\uparrow$ & $\uparrow$ & $\downarrow$ \\
$\widehat{K} \uparrow$ & $\uparrow$ & $\uparrow$ & $\uparrow$ & $\downarrow$ \\
$\bar{h} \uparrow$ & $\downarrow$ & $\uparrow$ & $\uparrow$ & $\downarrow$ \\
$\bar{c} \uparrow$ & $\downarrow$ & $\downarrow$ & $\uparrow$ & $\downarrow$ \\
$\bar{p} \uparrow$ & $\downarrow$ & $\downarrow$ & $\uparrow$ & $\downarrow$ \\
$z \uparrow$ & $\downarrow$ & $\downarrow$ & $\uparrow$ & $\downarrow$ \\
$E[x] \uparrow$ & $\uparrow$ & $\downarrow$ & $\downarrow$ & $\uparrow$ \\
\hline
\end{tabular}

(4) The value of $s$ is more sensitive to the parameters $\pi, \rho, n$ and less sensitive to other parameters. The higher the value of the parameter $\pi$, the higher the value of $s$. This means that as demand scale parameter $\pi$ increases, the company must raise selling price which will also directly impact positively the expected total profit. The higher the value of the parameters $\rho, n$, the smaller the value of $s$.

(5) When the expected value of the defective growing items $E[x]$ decreases, the expected total profit also decreases $E\left[\mathrm{TPU}^{*}\right]$.

(6) Changes on carbon emission parameters have a regular influence on the expected total profit $E\left[\mathrm{TPU}^{*}\right]$.

With the information of Tables $3-5$ is constructed Table 6 . Table 6 summarizes the sensitivity analysis study in a visual manner which is more helpful for the decision makers due to that these can more easily observe how changes in parameters affect to the decisions variables and the expected total profit per unit of time in order to take the best decisions based on numerical facts. 


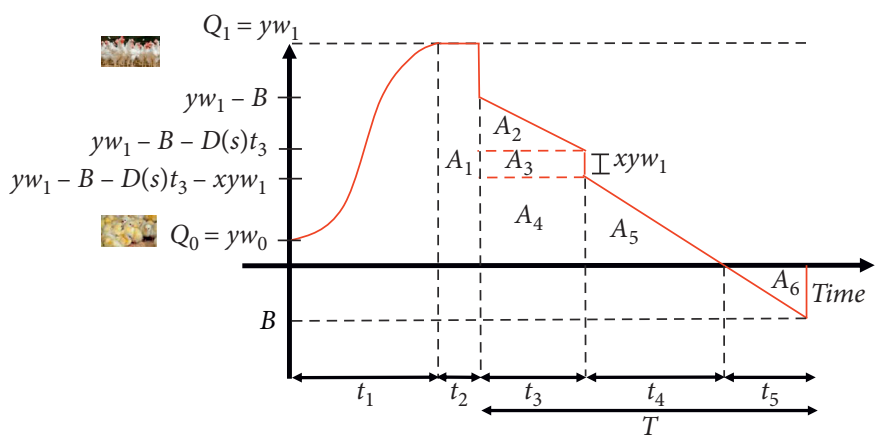

FIGURE 5: Inventory behavior through time.

\section{Conclusions and Future Research}

This paper develops an inventory model for growing items with imperfect quality and carbon emissions in which the demand rate is price sensitive according to a polynomial function. Furthermore, the shortages are permissible and these are fully backordered. To optimize the expected total profit per unit of time, some theoretical results are derived, and with these results, an effective and efficient solution procedure is developed. It is important to state that the algorithm generates the optimal solution to order quantity, backordering quantity, and selling price which maximizes the expected total profit per unit of time. The effects of carbon tax and the amount of carbon emissions are studied. Some important managerial insights are obtained from numerical examples and sensitivity analysis. The results show that carbon tax has a regular role on the reduction of carbon emissions. It is important to pay attention to quality and ensure that the percentage of defective items is kept to a minimum. Furthermore, if the setup cost increases, the company must raise selling price $s$, and when the demand elasticity parameter increases, the company must raise selling price which also directly impacts the total profit. Furthermore, the proposed inventory model is a generalized inventory model due the fact that several previously published inventory models are particular cases. It was found that the policy that permits shortages with full backordering is more economical that the one that avoids shortages. Moreover, it was also found that the proposed inventory model outperforms the inventory model of Sebatjane and Adetunji [40].

There are several possible extensions of the proposed inventory model that can be explored. These extensions constitute future research endeavors in the inventory management of imperfect growing items. For instance, consider to investigate the effect that only a percentage of defective items can be reworked, and the others must be eliminated immediately. Other research studies that can be conducted are to include new aspects such as stock-dependent demand, nonlinear holding cost, vendor-managed inventory (VMI) with consignment stock (CS), inflation, volume discounts, deterioration, trade credit, supply chain environment, and a vendor-buyer inventory model with multiple shipments, partial backordering, advertising, and multiple products subject to constrains such as space, budget, and time. These are, among others, some interesting and challenging subjects of ongoing future investigation that academicians and researchers would like to study in the future.

\section{Appendix}

\section{A. Determination of the Expected Holding Cost $(E[H c])$}

The holding cost is calculated by the multiplication of the unit holding cost $(h)$ and the total inventory accumulated during $t_{2}+t_{3}+t_{4}$, and this is the area above level zero in Figure 5. This area is computed as the sum of the areas $A_{1}+A_{2}+A_{3}+A_{4}+A_{5}$.

Considering Figure 5 , the five areas are defined as follows.

The area $A_{1}$ is obtained as follows:

$$
A_{1}=\left(t_{2}\right)\left(y w_{1}\right)=\left(\frac{B}{r}\right)\left(y w_{1}\right)=\frac{y w_{1} B}{r} .
$$

The area $A_{2}$ is found as follows:

$$
A_{2}=\frac{\left(t_{3}\right)(D(s))\left(t_{3}\right)}{2}=\frac{(D(s))\left(t_{3}^{2}\right)}{2}=\frac{(D(s))\left(\left(y w_{1}-B\right) / r\right)^{2}}{2}=\frac{(D(s))\left(y w_{1}-B\right)^{2}}{2 r^{2}} .
$$

The area $A_{3}$ is determined in the following manner:

$$
A_{3}=\left(t_{3}\right)\left(x y w_{1}\right)=\left(\frac{y w_{1}-B}{r}\right)\left(x y w_{1}\right)=\frac{y^{2} w_{1}^{2} x}{r}-\frac{y w_{1} x B}{r} .
$$

The area $A_{4}$ is defined as follows:

$$
\begin{aligned}
A_{4} & =\left(t_{3}\right)\left(y w_{1}-B-D(s) t_{3}-x y w_{1}\right) \\
& =\left(t_{3}\right)\left(y w_{1}(1-x)-B-D(s) t_{3}\right), \\
A_{4} & =\left(y w_{1}(1-x)-B\right) t_{3}-D(s) t_{3}^{2} .
\end{aligned}
$$


The area $A_{5}$ is given by

$$
\begin{aligned}
& A_{5}=\frac{\left(t_{4}\right)\left(y w_{1}-B-D(s) t_{3}-x y w_{1}\right)}{2}=\left(\frac{y w_{1}-B-D(s) t_{3}-x y w_{1}}{D(s)}\right)\left(\frac{y w_{1}(1-x)-B-D(s) t_{3}}{2}\right), \\
& A_{5}=\left(\frac{y w_{1}(1-x)-B-D(s) t_{3}}{D(s)}\right)\left(\frac{y w_{1}(1-x)-B-D(s) t_{3}}{2}\right)=\frac{\left(y w_{1}(1-x)-B-D(s) t_{3}\right)^{2}}{2 D(s)}, \\
& A_{5}=\frac{\left(y w_{1}(1-x)-B\right)^{2}-2\left(y w_{1}(1-x)-B\right) D(s) t_{3}+\left(D(s) t_{3}\right)^{2}}{2 D(s)}, \\
& A_{5}=\frac{\left(y w_{1}(1-x)-B\right)^{2}}{2 D(s)}-\left(y w_{1}(1-x)-B\right) t_{3}+\frac{D(s) t_{3}^{2}}{2} .
\end{aligned}
$$

The total inventory accumulated (TIA) during $t_{2}+t_{3}+$ $\mathrm{TIA}=A_{1}+A_{2}+A_{3}+A_{4}+A_{5}$. $t_{4}$ is computed as follows:

Substituting the corresponding areas,

$$
\begin{aligned}
\text { TIA }= & \frac{y w_{1} B}{r}+\frac{(D(s))\left(t_{3}^{2}\right)}{2}+\frac{y^{2} w_{1}^{2} x}{r}-\frac{y w_{1} x B}{r}+\left(y w_{1}(1-x)-B\right) t_{3}-D(s) t_{3}^{2} \\
& +\frac{\left(y w_{1}(1-x)-B\right)^{2}}{2 D(s)}-\left(y w_{1}(1-x)-B\right) t_{3}+\frac{D(s) t_{3}^{2}}{2}
\end{aligned}
$$

Simplifying,

$$
\begin{aligned}
\text { TIA } & =\frac{y w_{1} B(1-x)}{r}+\frac{y^{2} w_{1}^{2} x}{r}+\frac{\left(y w_{1}(1-x)-B\right)^{2}}{2 D(s)} \\
\text { TIA } & =\frac{y w_{1} B(1-x)}{r}+\frac{y^{2} w_{1}^{2} x}{r}+\frac{y^{2} w_{1}^{2}(1-x)^{2}-2 y w_{1}(1-x) B+B^{2}}{2 D(s)} \\
\text { TIA } & =\frac{y w_{1} B(1-x)}{r}+\frac{y^{2} w_{1}^{2} x}{r}+\frac{y^{2} w_{1}^{2}(1-x)^{2}-2 y w_{1}(1-x) B+B^{2}}{2 D(s)} .
\end{aligned}
$$

Taking the expected value of the total inventory accumulated (TIA), the following expression is obtained:

$$
E[\text { TIA }]=\frac{y w_{1} B(1-E[x])}{r}+\frac{y^{2} w_{1}^{2} E[x]}{r}+\frac{y^{2} w_{1}^{2} E\left[(1-x)^{2}\right]-2 y w_{1}(1-E[x]) B+B^{2}}{2 D(s)} .
$$

Rearranging terms,

$$
E[T I A]=\frac{y^{2} w_{1}^{2} E\left[(1-x)^{2}\right]}{2 D(s)}-\frac{y w_{1}(1-E[x]) B}{D(s)}+\frac{B^{2}}{2 D(s)}+\frac{y^{2} w_{1}^{2} E[x]}{r}-\frac{y w_{1} E[x] B}{r}+\frac{y w_{1} B}{r} .
$$

Finally, the expected holding cost $(E[H c])$ is given by 


$$
E[H c]=h\left[\frac{y^{2} w_{1}^{2} E\left[(1-x)^{2}\right]}{2 D(s)}-\frac{y w_{1}(1-E[x]) B}{D(s)}+\frac{B^{2}}{2 D(s)}+\frac{y^{2} w_{1}^{2} E[x]}{r}-\frac{y w_{1} E[x] B}{r}+\frac{y w_{1} B}{r}\right] .
$$

\section{B. Determination of the Backordering Cost $(B c)$}

The backordering cost is determined by the multiplication of the unit backordering cost $(b)$ and the total shortages accumulated during $t_{5}$, and this is the area $A_{6}$ shown below level zero in Figure 5. This area $\left(A_{6}\right)$ is obtained as follows:

$$
A_{6}=\frac{\left(t_{5}\right)(B)}{2}=\frac{(B / D(s))(B)}{2}=\frac{B^{2}}{2 D(s)} .
$$

Thus, the backordering cost $(B c)$ is given by

$$
B c=\frac{b B^{2}}{2 D(s)}
$$

\section{Sufficient Conditions for the Optimality}

For the sake of brevity, only the final equations are provided for the direct and cross second-order partial derivatives.
The direct second-order partial derivatives are given as follows.

The second-order partial derivative of equation (25) with respect to $y$ is as follows:

$$
\frac{\partial^{2} E[\operatorname{TPU}(y, B, s)]}{\partial y^{2}}=-\frac{B^{2}[h+b+\theta \hat{h}]+2\left(\pi-\rho s^{n}\right)[K+\theta \hat{K}]}{y^{3} w_{1}(1-E[x])}<0 .
$$

The second-order partial derivative of equation (25) with respect to $B$ is expressed as

$$
\frac{\partial^{2} E[\operatorname{TPU}(y, B, s)]}{\partial B^{2}}=-\frac{h+b+\theta \hat{h}}{y w_{1}(1-E[x])}<0
$$

The second-order partial derivative of equation (25) with respect to $s$ is given as follows:

$$
\begin{aligned}
\frac{\partial^{2} E[\operatorname{TPU}(y, B, s)]}{\partial s^{2}}= & -(n+1) \rho n s^{n-1}-\frac{\rho n(n-1) s^{n-2}}{w_{1}(1-E[x])}\left[v E[x] w_{1}-(p+\theta \widehat{p}) w_{0}-\frac{(K+\theta \widehat{K})}{y}\right. \\
& -(z+\theta \bar{z}) w_{1}-(c+\theta \bar{c})\left[\alpha t_{1}+\frac{\alpha}{\lambda}\left[\ln \left(1+\beta e^{-\lambda t_{1}}\right)-\ln (1+\beta)\right]\right] \\
& -\frac{(h+\theta \bar{h})}{r}\left[y w_{1}^{2} E[x]+B w_{1}(1-E[x])\right]<0 .
\end{aligned}
$$
follows.

The second-order cross partial derivatives are given as

The second-order cross partial derivative $\left(\partial^{2} / \partial y \partial B\right)$ of equation (25) is presented as follows:

$$
\frac{\partial^{2} E[\operatorname{TPU}(y, B, s)]}{\partial y \partial B}=\frac{B[h+b+\theta \hat{h}]}{y^{2} w_{1}(1-E[x])}
$$

The second-order cross partial derivative $\left(\partial^{2} / \partial y \partial s\right)$ of equation (25) is written in the following manner:

$$
\frac{\partial^{2} E[\operatorname{TPU}(y, B, s)]}{\partial y \partial s}=-\frac{\rho n s^{n-1}}{y^{2} w_{1}(1-E[x])}(K+\theta \widehat{K})+\frac{w_{1} E[x] \rho n s^{n-1}}{r(1-E[x])}(h+\theta \hat{h})
$$

The second-order cross partial derivative $\left(\partial^{2} / \partial B \partial y\right)$ of equation (25) is shown in the following way:

$$
\frac{\partial^{2} E[\operatorname{TPU}(y, B, s)]}{\partial B \partial y}=\frac{B[h+b+\theta \hat{h}]}{y^{2} w_{1}(1-E[x])} \text {. }
$$

$$
\frac{\partial^{2} E[\operatorname{TPU}(y, B, s)]}{\partial B \partial s}=\frac{\rho n s^{n-1}[h+\theta \widehat{h}]}{r} .
$$

The second-order cross partial derivative $\left(\partial^{2} / \partial B \partial s\right)$ of equation (25) is given as follows:

$$
\frac{\partial^{2} E[\operatorname{TPU}(y, B, s)]}{\partial s \partial y}=-\frac{\rho n s^{n-1}}{y^{2} w_{1}(1-E[x])}(K+\theta \widehat{K})+\frac{w_{1} E[x] \rho n s^{n-1}}{r(1-E[x])}(h+\theta \widehat{h})
$$


The second-order cross partial derivative $\left(\partial^{2} / \partial s \partial B\right)$ of equation (25) is

$$
\frac{\partial^{2} E[\operatorname{TPU}(y, B, s)]}{\partial s \partial B}=\frac{\rho n s^{n-1}[h+\theta \hat{h}]}{r} .
$$

Optimality is given as follows.

To prove the optimality of three decision variables, it is required to construct the Hessian matrix $H$, which is given as follows:

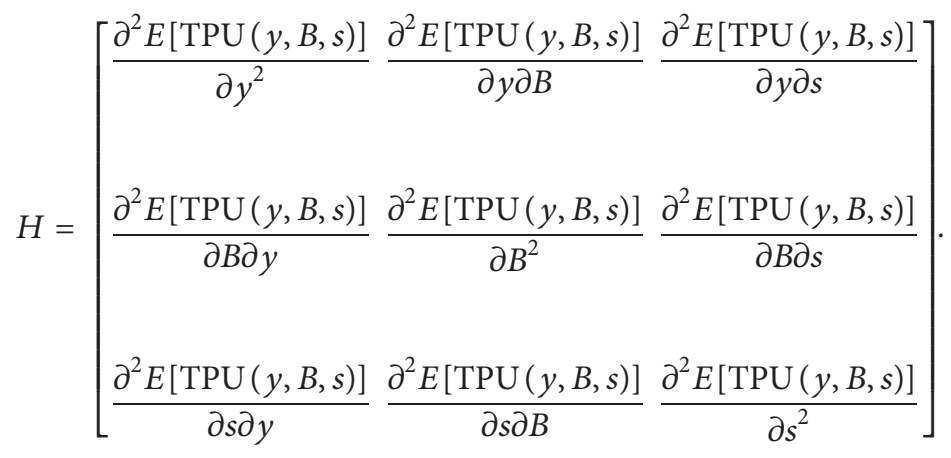

The sufficient conditions for optimality through the Hessian matrix $H$ are as follows:
$\operatorname{Det}\left(H_{1}\right)<0$, $\operatorname{Det}\left(H_{2}\right)>0$, and $\operatorname{Det}\left(H_{3}\right)<0$, where $H_{1}$, $\mathrm{H}_{2}$, and $\mathrm{H}_{3}$ are the following matrixes:

$$
\begin{aligned}
& H_{1}=\left[\frac{\partial^{2} E[\operatorname{TPU}(y, B, s)]}{\partial y^{2}}\right], \\
& H_{2}=\left[\begin{array}{cc}
\frac{\partial^{2} E[\operatorname{TPU}(y, B, s)]}{\partial y^{2}} & \frac{\partial^{2} E[\operatorname{TPU}(y, B, s)]}{\partial y \partial B} \\
\frac{\partial^{2} E[\operatorname{TPU}(y, B, s)]}{\partial B \partial y} & \frac{\partial^{2} E[\operatorname{TPU}(y, B, s)]}{\partial B^{2}}
\end{array}\right],
\end{aligned}
$$

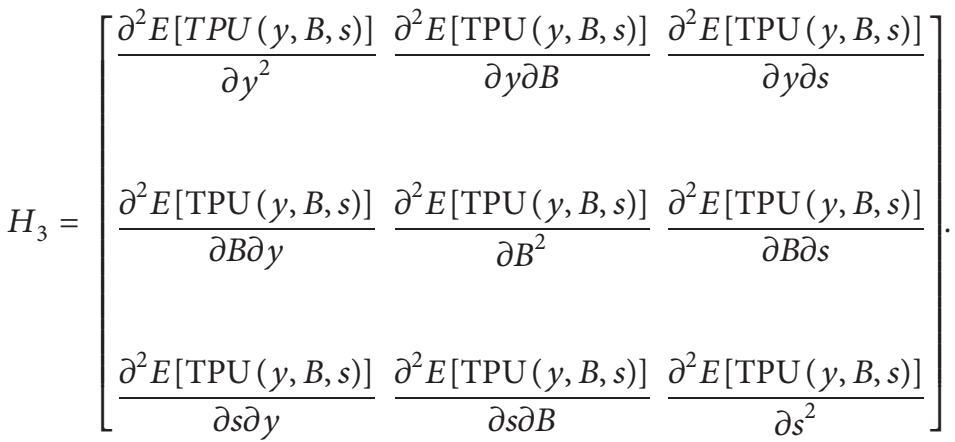


Thus,

$$
\begin{aligned}
& \operatorname{Det}\left(H_{1}\right)=\frac{\partial^{2} E[\operatorname{TPU}(y, B, s)]}{\partial y^{2}}=-\frac{B^{2}[h+b+\theta \hat{h}]+2\left(\pi-\rho s^{n}\right)[K+\theta \widehat{K}]}{y^{3} w_{1}(1-E[x])}<0, \\
& \operatorname{Det}\left(H_{2}\right)=\left(\frac{\partial^{2} E[\operatorname{TPU}(y, B, s)]}{\partial y^{2}}\right)\left(\frac{\partial^{2} E[\operatorname{TPU}(y, B, s)]}{\partial B^{2}}\right)-\left(\frac{\partial^{2} E[\operatorname{TPU}(y, B, s)]}{\partial y \partial B}\right)^{2}>0, \\
& \operatorname{Det}\left(H_{2}\right)=\left(-\frac{B^{2}[h+b+\theta \hat{h}]+2\left(\pi-\rho s^{n}\right)[K+\theta \widehat{K}]}{y^{3} w_{1}(1-E[x])}\right)\left(-\frac{h+b+\theta \hat{h}}{y w_{1}(1-E[x])}\right) \\
& -\left(\frac{B[h+b+\theta \hat{h}]}{y^{2} w_{1}(1-E[x])}\right)^{2}>0, \\
& \operatorname{Det}\left(H_{2}\right)=\left(\frac{2\left(\pi-\rho s^{n}\right)[K+\theta \hat{K}]}{y^{4} w_{1}^{2}(1-E[x])^{2}}\right)(h+b+\theta \hat{h})>0 \text {, } \\
& \operatorname{Det}\left(H_{3}\right)=\left(\frac{\partial^{2} E[\operatorname{TPU}(y, B, s)]}{\partial y^{2}}\right)\left(\frac{\partial^{2} E[\operatorname{TPU}(y, B, s)]}{\partial B^{2}}\right)\left(\frac{\partial^{2} E[\operatorname{TPU}(y, B, s)]}{\partial s^{2}}\right) \\
& +\left(\frac{\partial^{2} E[\operatorname{TPU}(y, B, s)]}{\partial B \partial y}\right)\left(\frac{\partial^{2} E[\operatorname{TPU}(y, B, s)]}{\partial s \partial B}\right)\left(\frac{\partial^{2} E[\operatorname{TPU}(y, B, s)]}{\partial y \partial s}\right) \\
& +\left(\frac{\partial^{2} E[\operatorname{TPU}(y, B, s)]}{\partial s \partial y}\right)\left(\frac{\partial^{2} E[\operatorname{TPU}(y, B, s)]}{\partial y \partial B}\right)\left(\frac{\partial^{2} E[\operatorname{TPU}(y, B, s)]}{\partial B \partial s}\right) \\
& -\left(\frac{\partial^{2} E[\operatorname{TPU}(y, B, s)]}{\partial y \partial s}\right)\left(\frac{\partial^{2} E[\operatorname{TPU}(y, B, s)]}{\partial B^{2}}\right)\left(\frac{\partial^{2} E[\operatorname{TPU}(y, B, s)]}{\partial s \partial y}\right) \\
& -\left(\frac{\partial^{2} E[\operatorname{TPU}(y, B, s)]}{\partial B \partial s}\right)\left(\frac{\partial^{2} E[\operatorname{TPU}(y, B, s)]}{\partial s \partial B}\right)\left(\frac{\partial^{2} E[\operatorname{TPU}(y, B, s)]}{\partial y^{2}}\right) \\
& -\left(\frac{\partial^{2} E[\operatorname{TPU}(y, B, s)]}{\partial s^{2}}\right)\left(\frac{\partial^{2} E[\operatorname{TPU}(y, B, s)]}{\partial y \partial B}\right)\left(\frac{\partial^{2} E[\operatorname{TPU}(y, B, s)]}{\partial B \partial y}\right)<0 .
\end{aligned}
$$

The abovementioned analysis proves that the function $E[T P U(y, B, s)]$ is strictly concave and shows that the Hessian is negative-definite. Therefore, the optimal solution for the decision variables $\left(y^{*}, B^{*}, s^{*}\right)$ exists and maximizes the expected total profit.

\section{Data Availability}

The data used to support the findings of this study are included within the article.

\section{Conflicts of Interest}

The authors declare that they have no conflicts of interest.

\section{Acknowledgments}

This research was supported by the Tecnológico de Monterrey Research Group in Optimization and Data Science (0822B01006).

\section{References}

[1] F. W. Harris, "How many parts to make at once," The Magazine of Mahnagement, vol. 10, no. 2, pp. 135-136, 152, 1913.

[2] P. K. Ghosh, A. K. Manna, and J. K. Dey, "Deteriorating manufacturing system with selling price discount under random machine breakdown," International Journal of Computational Engineering \& Management, vol. 20, no. 5, pp. 8-17, 2017.

[3] A. K. Manna, J. K. Dey, and S. K. Mondal, "Effect of inspection errors on imperfect production inventory model with warranty and price discount dependent demand rate," RAIRO-Operations Research, vol. 54, no. 4, pp. 1189-1213, 2020.

[4] M. A. A. Khan, A. A. Shaikh, G. C. Panda, and I. Konstantaras, "Two-warehouse inventory model for deteriorating items with partial backlogging and advance payment scheme," RAIRO-operations Research, vol. 53, no. 5, pp. 1691-1708, 2019.

[5] A. A. Shaikh, S. C. Das, A. K. Bhunia, G. C. Panda, and M. AlAmin Khan, "A two-warehouse EOQ model with interval- 
valued inventory cost and advance payment for deteriorating item under particle swarm optimization," Soft Computing, vol. 23, no. 24, pp. 13531-13546, 2019.

[6] M. A.-A. Khan, A. A. Shaikh, G. C. Panda, A. K. Bhunia, and I. Konstantaras, "Non-instantaneous deterioration effect in ordering decisions for a two-warehouse inventory system under advance payment and backlogging," Annals of Operations Research, vol. 289, no. 2, pp. 243-275, 2020.

[7] A. A. Shaikh, M. A.-A. Khan, G. C. Panda, and I. Konstantaras, "Price discount facility in an EOQ model for deteriorating items with stock-dependent demand and partial backlogging," International Transactions in Operational Research, vol. 26, no. 4, pp. 1365-1395, 2019.

[8] M. K. Salameh and M. Y. Jaber, "Economic production quantity model for items with imperfect quality," International Journal of Production Economics, vol. 64, no. 1-3, pp. 59-64, 2000.

[9] L. E. Cárdenas-Barrón, "Economic production quantity model for items with imperfect quality," International Journal of Production Economics, vol. 67, no. 2, p. 201, 2000.

[10] H. Wee, J. Yu, and M. Chen, "Optimal inventory model for items with imperfect quality and shortage backordering," Omega, vol. 35, no. 1, pp. 7-11, 2007.

[11] B. Maddah and M. Y. Jaber, "Economic order quantity for items with imperfect quality: revisited," International Journal of Production Economics, vol. 112, no. 2, pp. 808-815, 2008.

[12] S. M. Ross, Stochastic Processes, Wiley, New York, NY, USA, 1996.

[13] H. C. Chang and C. H. Ho, "Exact closed-form solutions for optimal inventory model for items with imperfect quality and shortage backordering," Omega, vol. 38, no. 3-4, pp. 233-237, 2010.

[14] L. E. Cárdenas-Barrón, “A complement to "A comprehensive note on: an economic order quantity with imperfect quality and quantity discounts", Applied Mathematical Modelling, vol. 36, no. 12, pp. 6338-6340, 2012.

[15] Y. Ghiami and P. Beullens, "Planning for shortages? Net present value analysis for a deteriorating item with partial backlogging," International Journal of Production Economics, vol. 178, pp. 1-11, 2016.

[16] Y. Zhou, C. Chen, C. Li, and Y. Zhong, "A synergic economic order quantity model with trade credit, shortages, imperfect quality and inspection errors," Applied Mathematical Modelling, vol. 40, no. 2, pp. 1012-1028, 2016.

[17] A. A. Taleizadeh, M. P. S. Khanbaglo, and L. E. CárdenasBarrón, "An EOQ inventory model with partial backordering and reparation of imperfect products," International Journal of Production Economics, vol. 182, pp. 418-434, 2016.

[18] J. Rezaei, "Economic order quantity and sampling inspection plans for imperfect items," Computers \& Industrial Engineering, vol. 96, pp. 1-7, 2016.

[19] G. Hua, T. C. E. Cheng, and S. Wang, "Managing carbon footprints in inventory management," International Journal of Production Economics, vol. 132, no. 2, pp. 178-185, 2011.

[20] M. C. Arslan and M. Turkay, "EOQ revisited with sustainability considerations," Foundations of Computing and Decision Sciences, vol. 38, no. 4, pp. 223-249, 2013.

[21] D. Battini, A. Persona, and F. Sgarbossa, "A sustainable EOQ model: theoretical formulation and applications," International Journal of Production Economics, vol. 149, pp. 145-153, 2014.

[22] T.-Y. Lin and B. R. Sarker, "A pull system inventory model with carbon tax policies and imperfect quality items," Applied Mathematical Modelling, vol. 50, pp. 450-462, 2017.
[23] S. Tiwari, Y. Daryanto, and H. M. Wee, "Sustainable inventory management with deteriorating and imperfect quality items considering carbon emission," Journal of Cleaner Production, vol. 192, pp. 281-292, 2018.

[24] N. Kazemi, S. H. Abdul-Rashid, R. A. R. Ghazilla, E. Shekarian, and S. Zanoni, "Economic order quantity models for items with imperfect quality and emission considerations," International Journal of Systems Science: Operations \& Logistics, vol. 5, no. 2, pp. 99-115, 2018.

[25] N. M. Modak, D. K. Ghosh, S. Panda, and S. S. Sana, "Managing green house gas emission cost and pricing policies in a two-echelon supply chain," CIRP Journal of Manufacturing Science and Technology, vol. 20, pp. 1-11, 2018.

[26] S. Sinha and N. M. Modak, "An EPQ model in the perspective of carbon emission reduction," International Journal of Mathematics in Operational Research, vol. 14, no. 3, pp. 338-358, 2019.

[27] Z. Li and J. Hai, "Inventory management for one warehouse multi-retailer systems with carbon emission costs," Computers \& Industrial Engineering, vol. 130, pp. 565-574, 2019.

[28] A. K. Manna, J. K. Dey, and S. K. Mondal, "Controlling GHG emission from industrial waste perusal of production inventory model with fuzzy pollution parameters," International Journal of Systems Science: Operations \& Logistics, vol. 6, no. 4, pp. 368-393, 2019.

[29] A. K. Manna, B. Das, and S. Tiwari, "Impact of carbon emission on imperfect production inventory system with advance payment base free transportation," RAIRO-Operations Research, vol. 54, no. 4, pp. 1103-1117, 2020.

[30] Y.-S. Huang, C.-C. Fang, and Y.-A. Lin, "Inventory management in supply chains with consideration of Logistics, green investment and different carbon emissions policies," Computers \& Industrial Engineering, vol. 139, Article ID 106207, 2020.

[31] U. Mishra, J.-Z. Wu, and B. Sarkar, "A sustainable production-inventory model for a controllable carbon emissions rate under shortages," Journal of Cleaner Production, vol. 256, Article ID 120268, 2020.

[32] A. A. Medina-Santana and L. E. Cárdenas-Barrón, “A sustainable inventory model considering a discontinuous transportation cost function and different sources of pollution," 2020, https://arxiv.org/abs/2005.03781.

[33] N. M. Modak and P. Kelle, "Using social work donation as a tool of corporate social responsibility in a closed-loop supply chain considering carbon emissions tax and demand uncertainty," Journal of the Operational Research Society, vol. 72, no. 1, pp. 61-77, 2021.

[34] J. Rezaei, "Economic order quantity for growing items," International Journal of Production Economics, vol. 155, pp. 109-113, 2014.

[35] Y. Zhang, L. Y. Li, X. Q. Tian, and C. Feng, "Inventory management research for growing items with carbon-constrained," in Proceedings of the 2016 35th Chinese Control Conference (CCC), pp. 9588-9593, IEEE, Chengdu, China, July 2016.

[36] M. Sebatjane, "Selected deterministic models for lot sizing of growing items inventory," M.S. thesis, University of Pretoria, South Africa, 2018.

[37] S. Khalilpourazari and S. H. R. Pasandideh, "Modeling and optimization of multi-item multi-constrained EOQ model for growing items," Knowledge-Based Systems, vol. 164, pp. 150$162,2019$.

[38] A. H. Nobil, A. H. A. Sedigh, and L. E. Cárdenas-Barrón, “A generalized economic order quantity inventory model with 
shortage: case study of a poultry farmer," Arabian Journal for Science and Engineering, vol. 44, no. 3, pp. 2653-2663, 2019.

[39] M. Malekitabar, S. Yaghoubi, and M. R. Gholamian, "A novel mathematical inventory model for growing-mortal items (case study: rainbow trout)," Applied Mathematical Modelling, vol. 71, pp. 96-117, 2019.

[40] M. Sebatjane and O. Adetunji, "Economic order quantity model for growing items with imperfect quality," Operations Research Perspectives, vol. 6, Article ID 100088, 2019.

[41] M. Sebatjane and O. Adetunji, "Economic order quantity model for growing items with incremental quantity discounts," Journal of Industrial Engineering International, vol. 15, no. 4, pp. 545-556, 2019.

[42] M. Sebatjane and O. Adetunji, "Three-echelon supply chain inventory model for growing items," Journal of Modelling in Management, vol. 15, no. 2, pp. 567-587, 2019.

[43] M. Sebatjane and O. Adetunji, "A three-echelon supply chain for economic growing quantity model with price- and freshness-dependent demand: pricing, ordering and shipment decisions," Operations Research Perspectives, vol. 7, Article ID 100153, 2020.

[44] M. Sebatjane and O. Adetunji, "Optimal inventory replenishment and shipment policies in a four-echelon supply chain for growing items with imperfect quality," Production \& Manufacturing Research, vol. 8, no. 1, pp. 130-157, 2020.

[45] A. Gharaei and E. Almehdawe, "Economic growing quantity," International Journal of Production Economics, vol. 223, p. $107517,2020$.

[46] Y. A. Hidayat, V. N. Riaventin, and O. Jayadi, "Economic order quantity model for growing items with incremental quantity discounts, capacitated storage facility, and limited budget," Jurnal Teknik Industri, vol. 22, no. 1, pp. 1-10, 2020.

[47] H. Mokhtari, A. Salmasnia, and J. Asadkhani, "A new production-inventory planning model for joint growing and deteriorating items," International Journal of Supply and Operations Management, vol. 7, no. 1, pp. 1-16, 2020.

[48] F. Nishandhi, "An economic order quantity model for growing items with imperfect quality and budget capacity constraint to limit the purchase," Solid State Technology, vol. 63, no. 6, pp. 7852-7858, 2020.

[49] N. Pourmohammad-Zia and B. Karimi, "Optimal replenishment and breeding policies for growing items," Arabian Journal for Science and Engineering, vol. 45, no. 8, pp. 7005-7015, 2020.

[50] A. R. Afzal and H. K. Alfares, "An inventory model for growing items with quality inspections and permissible shortages," in Proceedings of the 5th NA International Conference on Industrial Engineering and Operations Management, pp. 1153-1160, Detroit, MI, USA, August 2020.

[51] H. K. Alfares and A. R. Afzal, "An economic order quantity model for growing items with imperfect quality and shortages," Arabian Journal for Science and Engineering, vol. 46, no. 2, pp. 1863-1875, 2021.

[52] M. Sebatjane and O. Adetunji, "Optimal lot-sizing and shipment decisions in a three-echelon supply chain for growing items with inventory level- and expiration datedependent demand," Applied Mathematical Modelling, vol. 90, pp. 1204-1225, 2021.

[53] M. A.-A. Khan, A. A. Shaikh, G. C. Panda, I. Konstantaras, and A. A. Taleizadeh, "Inventory system with expiration date: pricing and replenishment decisions," Computers \& Industrial Engineering, vol. 132, pp. 232-247, 2019.

[54] M. A. A. Khan, S. Ahmed, M. S. Babu, and N. Sultana, "Optimal lot-size decision for deteriorating items with price-sensitive demand, linearly time-dependent holding cost under all-units discount environment," International Journal of Systems Science: Operations \& Logistics, pp. 1-14, 2020, In press.

[55] M. A. A. Khan, A. A. Shaikh, I. Konstantaras, A. K. Bhunia, and L. E. Cárdenas-Barrón, "Inventory models for perishable items with advanced payment, linearly time-dependent holding cost and demand dependent on advertisement and selling price," International Journal of Production Economics, vol. 230, Article ID 107804, 2020.

[56] M. A. A. Khan, A. A. Shaikh, G. C. Panda, I. Konstantaras, and L. E. Cárdenas-Barrón, "The effect of advance payment with discount facility on supply decisions of deteriorating products whose demand is both price and stock dependent," International Transactions in Operational Research, vol. 27, no. 3, pp. 1343-1367, 2020.

[57] G. C. Panda, M. A.-A. Khan, and A. A. Shaikh, "A credit policy approach in a two-warehouse inventory model for deteriorating items with price- and stock-dependent demand under partial backlogging," Journal of Industrial Engineering International, vol. 15, no. 1, pp. 147-170, 2019.

[58] S. Sinha, N. M. Modak, and S. S. Sana, "An entropic order quantity inventory model for quality assessment considering price sensitive demand," Opsearch, vol. 57, no. 1, pp. 88-103, 2020.

[59] N. M. Modak and P. Kelle, "Managing a dual-channel supply chain under price and delivery-time dependent stochastic demand," European Journal of Operational Research, vol. 272, no. 1, pp. 147-161, 2019.

[60] N. M. Modak, "Exploring Omni-channel supply chain under price and delivery time sensitive stochastic demand," Supply Chain Forum: An International Journal, vol. 18, no. 4, pp. 218-230, 2017.

[61] W. Shih, "Optimal inventory policies when stockouts result from defective products," International Journal of Production Research, vol. 18, no. 6, pp. 677-686, 1980.

[62] E. Silver, "Establishing the order quantity when the amount received is uncertain," INFOR: Information Systems and Operational Research, vol. 14, no. 1, pp. 32-39, 1976. 